Portland State University

PDXScholar

\title{
A Descriptive Study of the Relationship Between Cultural Sensitivity in the Acculturation Process and the Second Language Learning Process
}

Kazuko Ikeda

Portland State University

Follow this and additional works at: https://pdxscholar.library.pdx.edu/open_access_etds

Part of the International and Intercultural Communication Commons

Let us know how access to this document benefits you.

Recommended Citation

Ikeda, Kazuko, "A Descriptive Study of the Relationship Between Cultural Sensitivity in the Acculturation Process and the Second Language Learning Process" (1985). Dissertations and Theses. Paper 3442. https://doi.org/10.15760/etd.5326

This Thesis is brought to you for free and open access. It has been accepted for inclusion in Dissertations and Theses by an authorized administrator of PDXScholar. Please contact us if we can make this document more accessible: pdxscholar@pdx.edu. 
AN ABSTRACT OF THE THESIS OF Kazuko Ikeda for the Master of Arts in Speech Communication presented March 1, 1985.

Title: A Descriptive Study of The Relationship Between Cultural Sensitivity in the Acculturation Process and Second Language Learning.

APPROVED BY MEMBERS OF THE THESIS COMMITTEE:

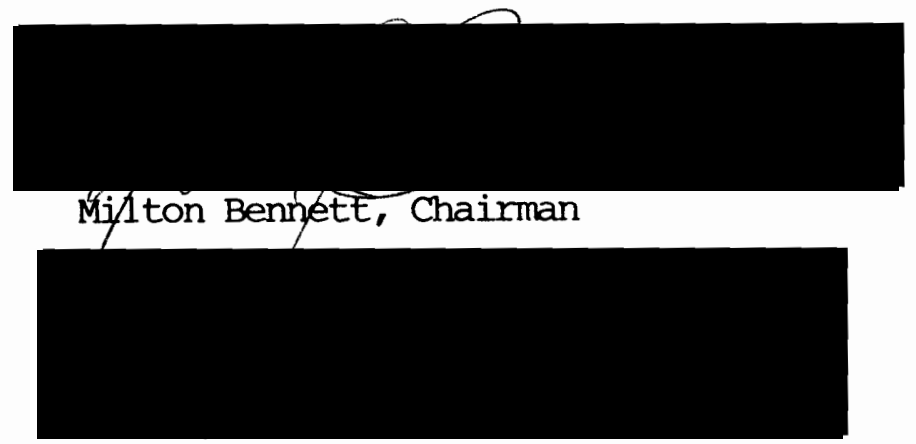

Theodore G. Grove

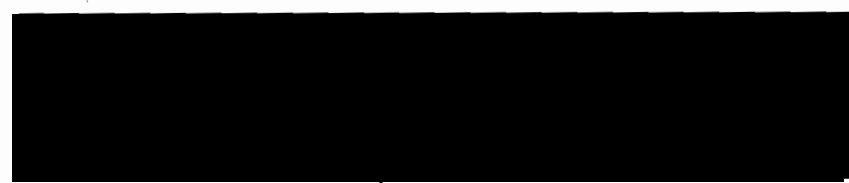

La Ray Barna

This is a study to investigate the association between the cultural sensitivity in the acculturation process and the second language learning process. This study is also a partial replication of the study by William Acton (1979) who developed the Professed Difference in Attitudes Questionnaire (PDAQ), which is utilized as a measurement instrument in this study. Acton's concept of socio-cultural equidistance is interpreted from the intercultural communication point of view. The results of the hypothesis testing are inconclusive and incongruous with Acton's study.

Applying systems analysis, the stages of cultural learning in the 
acculturation process provides a context for second language learning. The most developed stage of cultural sensitivity in the acculturation process, the most desirable situation for second language learning, is thought to be biculturality.

This biculturality is associated with socio-cultural marginality, i.e., cultural awareness, is one of the affective factors affecting second language learning. The role that cultural awareness plays in second culture and language learning is discussed.

Data were collected through the PDAQ and the Michigan Test. Subjects were international students registered at higher levels in the English as a Second language program at Portland State University and American Language Institute at Lewis and Clark College. The collected data were analyzed by the Pearson Product Correlation Coefficient program to test three hypotheses.

Hypothesis 1. There is a positive association between biculturality and second language proficiency.

Hypothesis 2. There is a positive association between socio-cultural marginality and second language proficiency.

Hypothesis 3. Subjects who have beenin the U.S. more than six months are more bicultural than those who have been in the U.S. less than six months.

These hypotheses were not supported. No direct positive correlation between cultural sensitivity, which is pertinent to biculturality, and language proficiency was found. Various weaknesses and problems of the study are discussed in four areas: (1) description of biculturality, (2) length of residence and other factors that might cause the incongruous results:(a) the subjects' initial language 
proficiency, (b) intensity of their immersion in the target culture and

(c) distribution of subjects, and (3) marginality, and (4) the Michigan Test. Finally, suggestions for further study are provided. 
A DESCRIPTIVE STUDY OF THE REIATIONSHIP BETWEEN

CULTURAL SENSITIVITY IN THE ACCULTURATION PROCESS AND THE SECOND LANGUAGE LEARNING PROCESS

by

KAZUKO IKEDA

A thesis submitted in partial fulfillment of the requirements for the degree of

\author{
MASTER OF ARTS \\ in \\ SPEECH COMMUNICATION
}

Portland State University

1985 
TO THE OFFICE OF GRADUATE STUDIES AND RESEARCH:

The members of the Committee approve the thesis of Kazuko Ikeda presented March 1, 1985

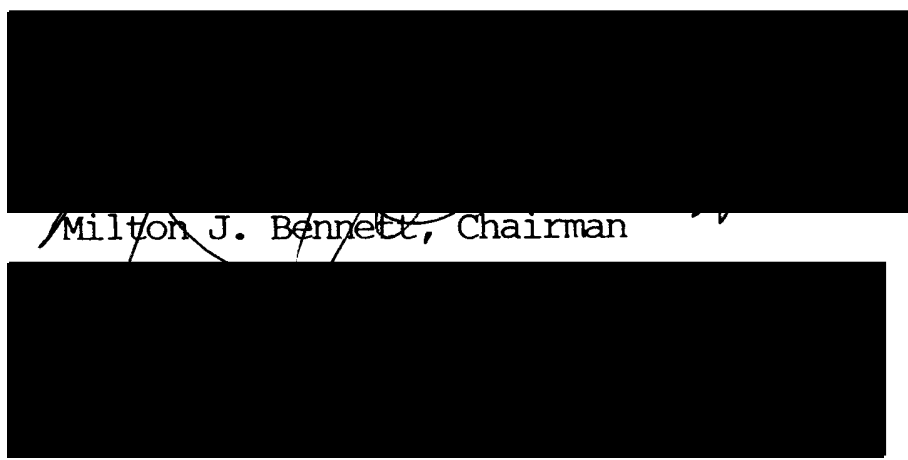

Theodore G. Grove

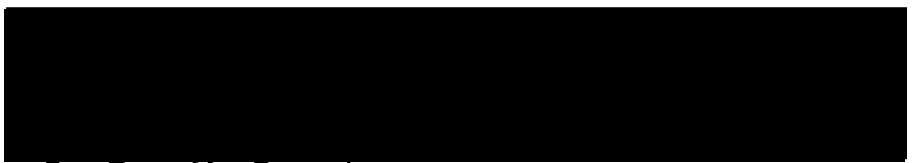

La Ray M. Barráa

APPROVED:

Ineodore G. Grove, Head, department of speech communication

Jum F.y Heatr, Dean of Graduate Studies and Research 
LIST OF TABLES .................... . . . LIST OF FIGURES. . . . . . . . . . . . . . . vi CHAPTER

I INTRODUCTION AND BACKGROUND. . . . . . . . . . . 1

II BICULTURALITY AND SECOND LANGUAGE LEARNING. . . . . . 7

Culture and Language: Systems Approach . . . . . . . .7 Culture Culture and Language as Systems Acculturation as Learning Process

Cultural Learning and Language Learning. . . . . . 14 Ethnocentric Stages

(I) Rejection

2LL in Rejection

(II) Defense

(A) Denigration or Superority 2LL in Denigration or Superiority

(B) Reversal 2LL in Reversal

(III) Universalism 2LL in Universalism

Ethnorelative Stages

Behavioral and Value Relativism

Biculturalisam 2LL in Ethnorelativism

III MARGINALITY AND SECOND LANGUAGE LEARNING. . . . . . . 25 Lexical Connotation

(a) Lexical Connotation: Argument

(b) Lexical Connotation: Predicate LC-Predicate: The Appraisal Function LC-Predicate: The Social Adjustment Function

Marginality and Cultural Awareness . . . . . . 35

VI RESEARCH DESIGN. ..................... 41

Research Questions

Research Hyothses

Definitions

Design of the Study 
Instruments

The Michigan Test

Reliability Study of PDAQ

The PDAQ Administration

Operational Hypotheses

Subjects

Procedures

Measurement Procedure

$\mathrm{V}$ RESULTS. . . . . . . . . . . . 50

Hypotheses Testing Results

Limitations . . . . . . . . . . . . 60

VI DISCUSSION AND SUGGESTIONS . . . . . . . . . . 66

Discussion

(1) Biculturality

(2) Distance from the American Culture

(3) Marginality

(4) Michigan Test

Conclusion

Suggestions

REFERENCE. . . . . . . . . . . . . . . . . . . 74

APPENDIX.. . . . . . . . . . . . . . . . . . 80 


\section{LIST OF TABLES}

TABLE

PAGE

I. Correlation between Michigan Test and Michigan Battery . . . 44

II. Correlation between TOEFL and Michigan Test. . . . . . . 45

III. Result of Reliability Testing on the PDAQ . . . . . . . .46

IV. Distribution Of Subjects by Native Language . . . . . . . .47

V. Results of Correlational Analysis of PDAQ on the Michigan

Test Scores. . . . . . . . . . . . . . 51

VI. Subject Distribution Based on the Michigan Test Score . . . .51

VII. Results of Trend Analysis: Correlation of the PDAQ Scores on the Michigan Test Scores. . . . . . . . . . 52

VIII. Contrast between "More Than 6 Mo." and "Less Than 6 Mo." by Mean PDAQ Scores .. . . . . . . . . . . . 56

IX. Distribution of Subjects Based on IOR and MT Scores. . . . 57

X. PDAQ Mean Scores for Three Groups. . . . . . . . . . . 57

XI. Percentage of Subjects Based on Their Native Language . . 67 XII. IOR and Intended IOR . . . . . . . . . . . . . 69 


\section{LIST OF FIGURES}

FIGURE

PAGE

1. Example of Semantic Differential Technique. . . . . . . . 31

2. The Format of the PDAQ. . . . . . . . . . . . . 34

3. The Experiential Learning Model . . . . . . . . . . . 36

4. The Example of the PDAQ Questionnaire. . . . . . . . . . . . 43

5. Scoring Three Distance Scores on PDAQ . . . . . . . . . 48

6. Example of the Triangle Model Based on PDAQ Scores. . . . . . .48

7. Triangle of the Allotted Scores of Figure 6. . . . . . . . . . 49

8. Triangular Representation and Abbreviated Symbols. . . . . . . 50

9. Scatter Plots for Group High. . . . . . . . . . . . 53

10. Scatter Plots for Group Middle . . . . . . . . . . 53

11. Scatter Plots for Group Low . . . . . . . . . . . . . . 54

12. Triangular Representation for Group High. . . . . . . • . . 54

13. Triangular Representation for Group Middle . . . . . . . . 55

14. Triangular Representation for Group Low . . . . . . . . . . 55

15. Scatter Plots for Group ISH. . . . . . . . . . . . 59

16. Scatter Plots for Group MSH. . . . . . . . . . . 59

17. Scatter Plots for Group MSL. . . . . . . . . . . . . 60

18. An Example of Triangular Model . . . . . . . . . . . . . . . . . .

19. A Triangle with Low Marginality. . . . . . . . . . . 70 
CHAPTER I

INTRODUCTION AND BACKGROUND

Second language learning in the target language culture is not merely acquiring a new language. It is also the acquisition of a new culture. In such an immersion situation, language learning takes place in the context of acculturation. The purpose of this study is to explore how the acculturation process affects second language learning by relating linguistic theories and intercultural communication theories.

This introduction provides the background for this study by reviewing previous research dealing with second language learning in relation to the acculturation process. The review of previous research in this section will set up a general perspective for this research, which is in part a replication of one of these past studies by William Acton (1979).

There are several studies on acculturation that point out the significance of language learning in the process of acculturation (Kim,1978, Brislin,1981), but there are not many that explain the impact of acculturation on second language learning.

Language learning theories can be identified with one of the two major domains: cognitive and affective. The cognitive domain deals with learning types, strategies, and styles. The affective domain deals with attitudes, motivation, personality, and so on. Since language learning 
is an intrinsic part of human behavior, and distinctively different from mechanical types of behavior like a computer, affective factors must be considered. It is necessary to examine these affective factors in order to find solutions to perplexing problems, which we have become more aware of through language teaching practices. In order to narrow the scope of this research, this study is limited to these affective factors

Various affective factors have been studied, including age (Krashen 1973, Krashen, Long and Scarcella 1979, Rosansky 1975), empathy, ego-permeability (Guiora, Beit-Hallahmi, Brannon, Dull \& Scovel 1972a, Guiora, Grannon, \& Dull 1972b), attitude (Gardner and Lambert 1972, Oller et al 1977a, 1977b, Spolsky 1969), motivation (Lukmani 1972) and personality (Fillmore 1979). In addition to these intrinsic affective factors, extrinsic factors, such as socio-cultural factors, have also been examined. This study is developed from the socio-cultural facet of learning where language and culture, linguistic and communication theories converge.

In 1975 John Schumann introduced social distance as an affective factor in second language learning. Social distance refers to the cognitive and affective proximity of two cultures which come into contact within an individual as he undergoes the acculturation process. Social distance, which is used in an abstract sense, consists of a number of parameters: dominance, integrative pattern, cohesiveness, congruence of the two cultures, attitudes and length of residence. Using these parameters, Schumann describes hypothetically a "good" or a "bad" language learning situation, and illustrates each situation with two actual cross-cultural contexts. He then draws the conclusion that the greater the social distance between the two cultures, the greater 
the difficulty the learner will have in learning the second language.

Applying the above concept, Schumann (1978) developed the Acculturation Model for second language learning and claimed that "the degree to which a learner acculturates to the target language group will control the degree to which he acquires the second language" (p.31).

Schumann's hypothesis of social distance, however, is problematic. One problem is the measurement of the actual social distance. The distance is measured by the researchers' subjective observation without giving any consideration to the learner's own perception of his learning environment. Also, the commensurate, linear relationship between the processes of acculturation and second language learning may be too simplistic.

Brown (1980b) offers a different hypothesis to explain the relationship between acculturation and second language learning. He incorporates acculturation stages into the language learning process and emphasizes the importance of the experience of culture shock and stress. Not only Brown, but also Larson and Smalley (1972) emphasize the significant impact of culture shock on second language learning. A learner who is in the stage of culture shock in the acculturation process undergoes disorientation. This disorientation reveals the fact that the learner is experiencing differences in values and behaviors in the new culture and feels anxious. By learning under anxiety, the learner solves some of the problems gradually and moves into the next stage, anomie, a state of feeling detached from the native culture. People in this stage often have feelings of chagrin mixed with a fearful anticipation of entering a new group. 
The stage of culture stress comes next in the general acculturative process. In this stage, learners make general progress and begin to understand cultural differences and to internalize some of the new cultural values. According to Brown, this stage is crucial for successful second language learning. He speculates that mastery or skillful fluency in a second language occurs somewhere at the beginning of this stage of acculturation. He hypothesizes that a successful second language learner should experience anxiety and stress for a certain amount of time because that anxiety is a manifestation of experiencing cultural differences; that is, different ways of thinking and feeling. Through this stressful experience, then, the learner should synthesize his linguistic knowledge with cultural knowledge.

The experience of cultural differences between the learner's native culture and the target language culture is explained as perceived socio-cultural distance by William Acton (1979). Acton quantifies the abstract concept of socio-cultural distance by using the Professed Difference in Attitude Questionnaire (PDAQ), which he developed for his doctoral dissertation. The questionnaire is a research tool to quantify the differences in how a learner perceives the connotation of concepts. In other words, scores on the PDAQ manifest the learner's perception of cultural value differences inherent in concepts.

Acton argues that it is not the observed social distance but the learner's own perception of the distance that affects the second language performance, since each learner sees his learning reality through his own frame of reference and acts or behaves according to this perception. This notion reflects well the social, interactional, 
and relativistic perspectives on the nature of perception.

In contrast with Acton's relativistic point of view, Schumann's analysis of social distance is based on the behaviorist assumption that a learner behaves in response to the given environment. This positivistic point of view is unilateral. In Schumann's study, each learning situation is observed and classified by a researcher and then evaluated as to whether it is a good second language learning situation or not. This could be misleading. There is probably no such thing as an absolutely good learning situation, which can be observed and interpreted in one way. A learner perceives the society through his own frame of reference. The individual learner behaves according to his own perception of learning situation, not someone else's, e.g. a researcher's. Therefore, learning is relative to individual differences. In addition, the learner's perception of learning situation is changing. Perception is an on-going process. The learner always renews or adjusts his frame of reference based on his perception. Thus his view of the society where the language acquisition takes place is changing constantly. It cannot be analyzed and measured from absolutistic and unilateral perspectives.

Acton found that the successful learner tends to maintain an equal socio-cultural distance from his native culture and from the target language culture. He claims that this is the optimum socio-cultural distance for successful second language learning. This socio-cultural distance is analyzed as the reflection of the process of adjustment where the learner has arrived at a sense of equilibrium, with the perception at the middle of two cultures. For purposes of this study biculturality will be used to mean being in equidistance 
from the two cultures.

In addition to this biculturality, marginality from the native and the target language culture is given consideration as another important affective factor. Acton's description of anomie, the detached feelings from the two cultures and the self, is considered as a phenomenon of marginality from the two cultures, which is a required state for cultural awareness. These two factors, biculturality and marginality, are the major constructs for the theoretical foundation of this study.

Chapter one is devoted to establishing the theoretical, systematic relationship between cultural learning and second language learning. Based on the systems approach, biculturality is defined as the manifestation of cultural sensitivity, one of the crucial characteristics for successful second language learning. Chapter two discusses the significance of marginality as one of the skills required for successful cultural learning. It is the detachment of the self from the process, the skills that enhance sensitivity to the intricate nature of lexical connotation. Chapters three, four and five deal with the design of the research, results and discussion respectively. 
CHAPTER II

BICULTURALITY AND SECOND LANGUAGE LEARNING

This chapter provides the theoretical foundation for biculturality as a significant factor for second language learning (2IU). The significance of biculturality is explained by the systematic analysis of culture and language; then acculturation is explained from the learning process perspective, so that acculturation and 2LL can be compared and contrasted directly as different but inseparable learning processes. Biculturality is described as the most desirable stage of cultural learning in the process of acculturation, reinforced by cultural sensitivity, which in turn provides the best second language learning context.

\section{Culture and Language: Systems Approach}

culture

A systems analysis approach provides the theoretical foundation for the significance of biculturality in 2LU by illustrating the relationship between language learning and acculturation processes.

Samovar and Porter(1982) describe culture as follows;

CUITURE is the deposit of knowledge, experiences, beliefs, values, attitudes, meanings, hierarchies, religion, timing, roles, spatial relations, concepts of the universe . . . acquired by a large group of people in the course of generations through individual and group striving. Culture manifests itself in patterns of language and informs of activity and behavior that act as models for both the common adaptive acts and the styles of communication that enable people to live in a society within a given geographic 
environment at a given state of technical development at a particular moment in time. (1982 p.31)

culture includes objects and institutions that people have created while participating in them. It also includes behaviors. According to Useem et al., culture can be defined as "the learned and shared behavior of a community of interacting human beings." (1963, p.169) This indicates that becoming a member of the community is done through learning and that culture is a behavioral phenomenon, which is comprised of verbal and nonverbal behaviors.

culture can be communication. It provides a frame of reference for our perception, behaviors, and ways of thinking. E.Hall (1973) elucidates the cormunicational aspect of culture, defining culture as "the way of organizing life, of thinking, and of conceiving the underlying assumption.... (Hall p.23). When people communicate their thoughts they are transferring culture. Since culture is the way of conceiving the underlying assumption, it determines and shapes perception and message decoding and encoding processes; it provides them information about which messages should be emphasized or ignored. It also gives information about the context and the relationship among people who are involved in the communication transaction. Culture is, thus, contextualized through daily human activities and creates a boundary for its own uniqueness.

The above ongoing creative process of culture is, in other words, creating a system that operates in its own unique way. Since various, distinctive cultures have been developed within their own unique environment, and have developed differently, each culture possesses its own unique communication system, and language behaviors. In the next section, culture and language are described as two interdependent 
systems.

\section{Culture and Ianguage as Systems}

In this section, the two concepts, language and culture, will be discussed as systems. Their interdependent nature of the two systems will be described in detail and, will be illustrated as the inner and outer wheels of these systems.

As noted in the preceding section, culture is more than just language. Language is the tool for verbal interaction. It is a part of cultural phenomena. As the Sapir-Whorf Hypothesis (Hoijer, 1982) postulates, culture manifests itself in language. Language shapes perception by defining the experience for the language user. However, the linguistic system cannot incorporate everything in the culture. As Useem et al. ( 1963 ) explain, manifold customs and values of the culture are anchored in tradition from which succeeding generations learn. The cultural themes, in Useem and Useem's terms, are seldom explained explicitly. They are learned by experiencing what is appropriate or inappropriate in various situations. The learning occurs while participating in activities of verbal and nonverbal interaction with people of the society. This is compatible with the contention made by E.Hall(1973) and D.Barnlund(1982) that culture is the totality of the whole communication practice.

Communication is done through various channels; it is also embedded in the context where communication takes place. Especially when meanings are contextualized, communication is carried out without verbalizing. According to Hall (1977) in "high context" cultural situations, where many meanings are embedded in the context, people do not need many words to communicate. For example, in Japan if the wife 
serves dinner late for no obvious reason, the husband will know that she is angry. This indicates that the husband and wife are cormunicating with very indirect subtle expressions without any verbal behavior. Also, through their cultural learning, both parties understand what this situation, serving dinner late, communicates, and use the whole situation as the most effective communication tool. Thus, language is not always necessary to communicate certain meanings. People know what is appropriate or inappropriate to do mainly through subtle nonverbal communication interactions. People internalize the context as a whole through experience, some of which is internalized without being defined with words.

In summary, words cannot explain everything that takes place in reality. An event is more complex than language. Language is an abstraction of events. Various events and communication situations are internalized without verbal definitions. In order to understand situations and events more fully, we need to know the context which is given by culture. This context governs our perception and communication transaction, which in turn governs language usage.

When we apply the systems approach to the above discussion, culture should be the larger system that includes the language within it. Both systems are dynamic and processual. They are open systems; they are open to changes. Language is the inner wheel of the culture wheel. The outer border of the language system is simultaneously the inner border of culture, and because of this, each influences the other. There are continuous transactions back and forth across the boundaries of language and culture. When language changes, culture changes and vice versa. When people start using "chairperson" instead 
of "chairman", it implies a modification in the cultural system as well. On the other hand modification in cultural behavior, for example, alteration in parents' power in a society might cause a change in language. For example, in Japanese "nakodo-oya" (matchmaking parents) has become simply "nakodo" since match makers do not function like parents any more in Japanese culture. Thus, no system is independent of the other. Each exists in and creates the context of the other. They are interdependent. The larger system sets a limit on the nature of the smaller system by providing perspectives from which to examine the process of the smaller system. Therefore, it is culture that examines the adequacy or inadequacy of language. Actually it is cultural values that exert the function of evaluation (Janes, Haiman, Barnlund 1980). In summary, "any system is born out of the womb of surrounding systems, and each creates opportunities and places limits on the others. Without culture there would be no music, no language, in short no means by which individuals could create distinctive personalities" (Janes, Haíman, Barntund p.33).

\section{Acculturation as Learning Process}

In order to compare and contrast acculturation and second language learning, acculturation can be explained as a learning process. All people are born into a culture and participate as members of that cultural group. People are nurtured and affected by the culture; their perceptions, values, and attitudes that constitute their psychological and social aspects are molded by culture. This process can be labeled as "learning": the learning of a culture.

M.R.Singer(1982) emphasizes the subjective nature of the perceptual process in cultural learning, contending that, in terms of 
human behavior, there exists only subjective reality for man; i.e., the universe exists only as an individual perceives it. This notion acknowledges the existence of culture only within an individual.

However, there is an objective reality. An individual is born into some kind of cultural situation although each person perceives it subjectively and affects and is affected by it differently. The whole process of becoming a member of that cultural group is summarized by Berger and Luckman(1967) from the social interactionistic point of view: society or the cultural group possesses objective facticity and activities express subjective meanings and that constitute the particular society. According to Berger and Luckman, while participating in cultural activities, people internalize objective reality and in turn form an internal reality. They then externalize their internal reality by way of role behaviors. This transactional process of externalization and internalization of reality is continuous. People create the reality by doing, then internalize their creation by participating in that reality. Therefore, people who are born in the same cultural group share a similar pattern of constructs of reality due to the fact that they share a common environment, i.e., similar objective facticity and similar activities that express subjective meanings. As a result, their outlook and behavioral patterns become very similar in a particular way.

However, if an individual is moved into a completely different cultural environment, his primary internalized reality does not help him much to understand the events and activities occurring in the new environment. He has to confront various unknowns and unfamiliar situations and has to learn to cope with them. This learning process 
of the secondary culture is the process of acculturation.

The acculturation process takes place following a somewhat common
progression,
(1) Euphoria,
(2) Culture shock, and
(3) Adjustment.

Gullahorn and Gullahorn (1963) describe this progression as follows:

Initially the sojourners report feelings of elation and optimism associated with positive expectations regarding interaction with their hosts. As they actually become involved in role relationships and encounter frustrations in trying to achieve certain goals when the proper means are unclear or unacceptable, they become confused and depressed and express negative attitudes regarding the host culture. If they are able to resolve the difficulties encountered during this crucial phase of the acculturation process they then achieve a modus vivendi enabling them to work effectively and to interact positively with their hosts. ( p.34)

Euphoria, the first stage of acculturation, refers to a state that takes place at the beginning when people meet a new culture. As long as an individual sees and internalizes facticities in the new culture firmly with his own frame of reference, things are seen as exciting and exotic.

However, this newness will fade away soon and cognitive and affective contradiction in the new culture will arise (Brown $1980 \mathrm{~b}$ ). The newcomer is about to become disoriented. This is culture shock, a stressful transition shock that results from the difficulty of coping with unfamiliar situations. Things that might be routine in the native culture can become a problem in the new situation because of unfamiliarity. People experience psychological and physical discomfort. As time goes by, people solve some of the problems and move toward adjustment. At this stage, they consciously or unconsciously undergo different types of adjustment.

There are four stages of ethnocentric adjustment and two stages of ethnorelative adjustment. These six stages are adopted from 
Bennett's (1984) categorization.

Stages of Adjustment

The Ethnocentric Stages

I. REJECTION

II. DEFENSE

A. Denigration/Superiority

B. Reversal

III. UNIVERSALISM

The Ethnorelative Stages

I. Behavioral and Value Relativism

II. Biculturalism (Multiculturalism)

(Adopted from Bennett, 1984)

The above stages are somewhat arbitrary and remain theoretical states because in reality none of them exist in their pure form; no one individual lives in one stage all the time. These stages are all processual; people are moving from one stage to another continuously.

These different stages of cultural learning process will be described in the next section, and will be compared with the second language learning (2LU) process by applying a systems approach.

\section{Cultural Learning and Language Learning}

Based on the systematic relationship between culture and language, the cultural learning process provides the context for the language learning process. Change in one process causes change in the other. It is my contention that different cultural learning processes impose some kind of context upon the nature of 2IL processes. Both processes are interdependent and transactional. The following is an 
attempt to support this contention theoretically.

Ethnocentric Stages

Ethnocentrism can be defined as "assuming that the world view of one's own culture is central to all reality (Bennett 1984 p.9)."

\section{I) Rejection}

Rejection is one of the extreme forms of ethnocentrism. It is a form of denial of cultural difference. It creates boundaries around one's own culture and leads one to deny perceiving differences.

In this situation an individual keeps his or her primary cultural identity strongly and keeps the interaction with the host culture to a minimum. He does not share any institution or does not participate in host cultural activities. On the contrary, he participates only in the church or school and uses the grocery stores of his own ethnic group.

\section{LI in Reiection}

When an individual undergoes rejection, he communicates only minimally with the host culture and people. Given this context for language learning, this person would not be very successful in learning the language of the host culture. Not wanting to learn the culture itself denies the person the possibility of language learning, because language is the system that is a part of culture. Denial of culture learning takes away the basis and context for language learning.

\section{II) Defense}

At this stage, cultural difference is perceived as threatening, and hence one needs to develop some kind of defense in order to face this cultural difference. Two stages are discussed. One is 
"denigration or superiority" and the other is "reversal."

\section{A. Denigration or Superiority}

This stage is characterized by some degree of negative attitude toward cultural difference. An individual who is at denigration stage perceives and evaluates the host culture negatively, and he may conceive negative stereotypes of people in the host culture. Superiority is another stage of defense. This stage is characterized by the positive evaluation of one's own culture, rather than denigration of others. The common thread between the two is that difference is seen as threatening and defense towards other cultures is felt necessary.

\section{LL in Denigration or Superiority}

It is quite common that an individual who denigrates the host culture or who believes that one's own culture is much better than the host culture does not perceive the necessity of learning the new language. Learning the host language is felt somewhat degrading, and one may not be motivated to learn the language at all. Thus diffusion of negative attitude toward culture over language delimits the nature of the language learning process. A typical situation is that of English people in India or the Japanese in Korea: the situation between the colonizers and the colonized.

However, it is reported that, if the negative attitude toward the host culture is so strong that the learner perceives the host culture as his enemy (Larson and Smalley 1972), he often becomes a successful second language learner. He learns the language in order to "win the war". Thus the strong negative attitude implements motivation for 
cultural learning. It in turn provides the context for language learning. Language, in this case, might be seen as a tool to understand the opponent, its culture and people, in order to defeat them.

\section{B. Reversal}

This is a reversed form of denigration. "Reversal involves a denigration of one's own culture and an attendant assumption of superiority of a different culture" (Bennett 1984 p.21). Unlike denigration or superiority, people who are at this stage adopt the host language and behavior as primary and reject their own native culture and language. Reversal may appear less ethnocentric than previous stages, but it is as ethnocentric as they are. It only changes the culture that is different, i.e. the native culture, and the difference is perceived as threatening. This is still a monolithic cultural point of view. Only one culture is accepted.

\section{$\underline{2 \mathrm{~L} \text { at Reversal stage }}$}

The reversal stage also occurs mainly due to the lack of sensitivity toward cultural differences. People at this stage are prone to perceive what they want to see. When an individual holds a very strong positive evaluation of differences, he will be eager to pick up everything new and different from his native culture. As a result, he quickly rejects his own language and cultural values. This is the process of selective perception. A case of non-learning in $2 \mathrm{LL}$ illustrates this situation.

Shapira(1978) reported a non-learning case of Zoira who had been in the U.S. for three years and was satisfied with her English. Zoira 
thought she had achieved her goal of being able to communicate with native speakers. Her case parallels the ethnocentric cultural learning of the reversal stage.

The positive perception of others' response to her language behavior is a significant definitive factor of her $2 \mathrm{LL}$ process. Because Zoira had an impression that people who came in contact with her were satisfied with her English, her confidence about her English usage ability was reinforced. Therefore, she never questioned if she should learn more rules and sounds. As a result she fossilized grammar rules and pronunciation.

This situation can be explained by the "rule fossilization" theory by oller et al. (1977a). They hypothesized that second language learners fossilize grammar rules when they receive positive feedback through both the affective channel and cognitive channel.

Types of Feedback in Rule Fossilization Model Affecive Feedback

Positive: "I like it" (more of the same)

Neutral: "Waiting..." (reaction undecided)

Negative: "I don't like it" (try something else)

Cognitive Feedback

Positive: "I understand" (message and direction are clear)

Neutral: "Still processing..." (undecided)

Negative: "I don't understand" (message and/or direction are not clear)

(Oller and Vigil p.286)

Various combinations of these two types of feedback are possible; (1) Positive affective feedback and negative cognitive feedback encourage the receiver to change her behavior. However, (2) negative affective feedback regardless of the degree of cognitive feedback causes the receiver to withdraw from interaction. (3) Both positive affective and 
cognitive feedback encourage the receiver to interact, but often reinforce incorrect forms of language. Learners tend to fossilize their language, because they see no need for change.

Given this hypothesis, it is important to consider the significance of the receiver's perception and interpretation of feedback. We are not sure how others responded to her all the time. We only know through the record that Zoira perceived the feedback from others positively both in affective and cognitive aspects. If the person is insensitive to subtle behavioral differences and preoccupied and prejudiced by the positive evaluation of differences about the new culture, she is less likely to perceive the negative evaluation of her behaviors. Her positive attitude blinds her from seeing anything negative about the new culture. Hence she is prone to fossilize her language and will not be very successful in language learning. The reversal stage of adjustment may provide a context for fossilization in second language learning in general.

\section{Universalism}

According to Bennett (1984) this stage is beyond the previous stages in terms of cultural sensitivity. Universalism involves an "attempt to 'bury' difference under the weight of cultural similarities" (Bennett p.23). Although cultural difference is acknowledged, it is minimized or trivialized. Cultural differences are treated as less significant than cultural similarities.

When an individual assumes similarity in cultural values, he does not experience contradicting cultural value differences because he minimizes the differences and tries to ignore their significance. This person lacks awareness and sensitivity to cultural distinctiveness and 
dissimilarity. Consequently, he assumes that if he behaves in good will, there will be no problem, so he behaves naturally based on his own cultural patterns of behaviors. Thus, this naive assumption of similarity hinders the ability to observe and experience distinctive cultural differences.

This is exactly the situation that Bieri (1955) found in his study of cognitive complexity-simplicity and predictive behavior.

Condition of cognitive simplicity reflects an incomplete differentiation of the boundaries between self and the external world, leading to unwarranted assumption of similarity between self and others. (p.267)

Hence an individual cannot perceive complex, subtle differences due to cognitive simplicity, in other words, due to a lack of sensitivity.

\section{$\underline{2 \mathrm{LL} \text { in Universalism }}$}

As Bieri (1955) explains, the assumption of similarity is the manifestation of cognitive simplicity. Assumptions are often made on the basis of insufficient and inadequate evidence. In language learning, this tendency will be reflected in the perception of one's own language usage. The learner cannot perceive the feedback of the native speakers appropriately because of his assumption of similarity. $\mathrm{He}$ is prone to misunderstand or totally miss some important cues necessary to improve his language use, since these cues, verbal or nonverbal, are culturally bound and relative to each culture. If the learner is not aware of his language usage in culturally bound communication situations, he is not very successful in $2 \mathrm{LL}$. He cannot be a good communicator. Even if he can handle the linguistic system, he cannot combine that linguistic knowledge with cultural knowledge. This is the situation explained by Brown (1980b) as failure of 
synchronizing linguistic and cultural development.

\section{Ethnorelative Stages}

The basic assumption of ethnorelativism is that cultures are different, neither good nor bad, but just different. "...cultures can only be understood relative to one another.... One's own culture is not any more central to reality than any other culture...." (Bennett 1984 p.31).

Behavioral and Value Relativism

At this stage, individuals experience cultural value differences and pass through adjusting processes accordingly. According to Hoopes (1979), an individual who is in this process adjusts his behavior in order to achieve his goals in the host society, but he does not incorporate or internalize the values of those particular role behaviors.

However, Brislin(1981) asserts that people would not behave in certain ways because of convenience of role playing for temporal adjustment. Instead, people internalize beliefs and values behind these particular behavioral patterns and then behave accordingly. Internalization of underlying beliefs and values, here, is still limited to certain behaviors because people in this category adopt only certain roles and behaviors that are consistent with their own goals. They do not change their behavioral patterns and values as a whole. University students who are simply concerned about obtaining a degree from the host country university might be a good example of this case. When people start internalizing and incorporating the host cultural values and beliefs as a whole, they move one step forward to 
biculturalism.

Biculturalism

Biculturalism can be considered as an advanced stage of behavioral and value relativism. Cultural sensitivity facilitates recognition, legitimization, acceptance, and appreciation of the fundamental differences among cultures. In contrast with ethnocentrism, ethnorelativism facilitates perception of various differences due to sensitivity that is interpreted as cognitive complexity (Bieri, 1955). The more cognitively complex the person is, the more accurate his perception of others' behavior is.

The increasing possibility of perceiving differences is the process of learning analogous to the process of differentiation in human development (Berry, 1975). As children grow older, they tend to become more differentiated both cognitively and affectively. In cultural learning, differentiation itself is the process of learning. The implication, here, is that the more successful a learner is and the more sensitive he is, the better able he is to see a higher degree of diversity in reality. People who reach these stages are very sensitive to cultural differences.

A bicultural person, then, internalizes and contextualizes behavioral patterns as well as their underlying values; hence, his behavior in the new cultural situation comes out naturally and is accepted comfortably by the people in the host culture. Whatever his goal is, he is genuinely applying the new cultural frame of reference that is required and appropriate to the context.

He is shifting his frame of reference according to the situation. Although the individual's primary culture suffers some changes, he 
develops a dual cultural personality that is constantly shifting and changing (Lum, 1982). Therefore, his behavior may not be purely or wholly, say Japanese or American, but may be a combination of both. Yet his behavior in both cultures is quite appropriate and he is comfortable with both. This stage can be further developed to multicul turalism.

A multicultural person can interculturally cormunicate by understanding and applying several frames of reference that are required for the situation. Cultural awareness and sensitivity to cultural differences, i.e., cultural relativity, are essential for the bicultural or multicultural person. (Cultural awareness will be discussed in more detail in chapter two.)

\section{$2 \mathrm{LI}$ in Ethnorelativism}

When people reach the ethnorelativistic stages, the situation will be very different from the ethnocentric stages. Cultural awareness and sensitivity are germane here. A bicultural person's perception is more differentiated than that of people who are in rejection; hence a bicultural person has more possibilities to perceive differences between his own cultural values and behaviors and those of the host culture.

The characteristics of cultural leaming of a bicultural person provide a supportive context for language learning. A second language learner who is able to perceive and sense various behavioral patterns and values should be able to understand the complexity of meanings of language and subtle nuances which are interwoven in linguistic systems. The high degree of cognitive and psychological differentiation should facilitate sensitive perception of subtlety such as connotation of 
words. As discussed, language learning is a part of cultural learning. It is not simply learning about the system of the language. If the person learns the system alone without incorporating cultural knowledge, he may become a so-called "fluent fool."

The characteristics of a bicultural person also provide the basis for better language performance. Having acquired a differentiated cultural perception, he is now able to behave accordingly, continuously shifting his frame of reference in order to act.

Bieri (1955) suggests that a high degree of differentiation can be labeled as empathy. It means that a learner can behave as the other person expects him to do and his appropriateness in the context raises the comfort level in the communication situation; hence, the interaction between the learner and native speakers increases both in quality and quantity. As a consequence, the chances of improvement in language use increase and the whole process of interaction forms a positive circulation. Bicultural learning, thus, characterizes more successful language learning.

It is also important to consider cultural awareness. These bicultural people are aware of their own culture, its values and behavioral patterns as well as those of the host culture. Cultural awareness and sensitivity have a mutual effect on each other. The vital role cultural awareness plays in second culture and language learning will be discussed in the next chapter. 


\section{MARGINALITY AND SECOND LANGUAGE LEARNING}

This chapter provides the theoretical basis for marginality as one of the skills required for successful cultural and second language learning. Through the discussion in the previous chapter, it is now clear that cultural learning provides a context for second language learning and because of that, sensitivity in biculturalism may be an important factor for a good language learner. The discussion of cultural learning, in this chapter, will be narrowed down to the learning of connotation, where cultural and linguistic learning overlap. A general rationale for using a semantic differential type of questionnaire as a research tool will be also given in this chapter.

First, lexical connotation will be explained because this study is a partial replication of Acton's relational analysis of perception of lexical connotation which is manifested in the semantic differential type of questionnaire, named Professed Difference of Attitudes Questionnaire. Based on his study, the function of the PDAQ is illustrated from a socio-cultural point of view making a theoretical connection with biculturality. Second it is argued that for effective connotation learning, one should be aware of cultural differences. Awareness is then interpreted as marginality, which ultimately enhances the sensitivity in both cultural and language learning. 
Lexical Connotation

In general, connotation is defined as the implied meaning in a communication situation. Here, the discussion of connotative meaning is restricted to the word level rather than larger linguistic units such as sentences. The word level connotation is called lexical connotation. William Acton (1979) provides a definition of lexical connotation as follows.

The lexical connotation of a word consists of those concepts, objects, feelings and experiences generally associated with or implied by or suggested by a word that one would not expect to find discussed explicitly in the lexicon of a linguistic theory or a common dictionary. $(1979, \mathrm{p} .9)$

Lexical connotation is a phenomenon that is at the border between language and non-language, linguistic and non-linguistic. It is in the area that overlaps with one of the psychological constructs of attitudes. Attitude is the abstract construct that is centered in human beings; lexical connotation is similar in the sense that it is an attitude that manifests itself in words.

Four aspects of lexical connotation will clarify its meaning as used in this study. The first aspect is that connotation is the secondary meaning. It is not essential. It is different from the intended meaning that follows some logical interpretation of rules which is considered essential for understanding the intended or implied meaning, like meanings obtained by pragmatic rules. second, the lexical connotation is "one aspect of culture in that it represents one area in which a group of people tend to agree as to the values and 'attitudes' that are attached to certain concepts" (Acton 1979, p.11). Third, connotation is, as defined, implicit and not found in 
dictionaries and linguistic theories. Because connotation is the meaning attached to the denotative meaning, it is subject to one's perception. For example, the word "honeymoon" connotes various meanings. Watzlawick (1977) discusses Laing, Phillipson, and Lee's example:

Now, eight years later, they discover that they had approached the situation "honeymoon" with two very different interpretations, naively assuming that, "of course," it had the same meaning in the other's "language" as well. For the wife, the honeymoon was the first opportunity to practice her newly acquired social role. . . - The husband's interpretation of "honeymoon," however, was of a period of exclusive togetherness. . . (1977 p.8)

The fourth aspect is that lexical connotation is processual. According to Acton's words, it "represents a strong recursive element in potential meaning of a word." (p.29) Whenever a word is used, one or more concepts are associated with a word, particularly when a word is used metaphorically. This means that whenever a word is used, a slightly different lexical connotation is added; in other words, it changes and becomes potentially more complex.

The study of connotation in linguistics has generally been neglected. Due to the influence of Skinner's behaviorism which focused on observable overt action, linguists dealt with denotative meanings and structures of the language which were easy to describe. For a long time connotation was treated simply as indices. Although it has been recognized that words communicate more than their literal meanings, connotation, because of its elusive and subjective nature, has been omitted from most formal studies. Despite the fact that ogden and Richard (1949) formally established two categories of meaning or language use, the scientific (denotative and cognitive) and the emotive (connotative and non-cognitive), linguists still focus their discussion 
on denotative, cognitive aspect of the language.

However, there are some innovative studies about language use that include connotation such as that by Henle (19.72). Henle explains that connotation is not merely an index that can be identified as belonging to a particular dialect within a culture, but it implies that the learner should understand what kind of attitudes and emotions will be evoked by the expression if he wants to use it. Henle treats lexical connotation as part of cultural perception and learning. This notion is further developed by Acton.

In this study, Acton's schema for some aspects of language will be modified and used as the basis of the discussion of relation between perception of lexical connotation and cultural learning, i.e., acculturation. This discussion, then, will explicate the influence of learning connotation on second language learning by demonstrating that it is cultural learning which gives a context for second language learning.

Acton's schema consists of three main categories;

Acton's Schema for Meanings of Words

1) Primary Conceptual Content

e.g., denotation, reference etc.

2) Conditions of Usage

e.g., sociolinguistic, situational etc.

3) Lexical Connotation

Secondary Conceptual content

a) Arguments (cognitive)

b) Predicates (cognitive and non-cognitive)

c) Emotive Content (non-cognitive) 
From the above schema, Lexical Connotation and its subcategories, Arguments and Predicates, are selected for discussion. These are the categories that describe and elucidate the socio-cultural aspect of lexical connotation, which is the key concept to study the connection between language learning and cultural learning processes.

\section{(I) Lexical Connotation}

Lexical connotation is the secondary conceptual content. It is implicit, processual, and cultural as described at the beginning of this chapter.

\section{(a) Lexical Connotation: Argument}

Lexical Connotation( $L C$ )-Argument is a nominative entity. It is asserted by the predicate. 'Argument,' here, is used like the term in logic. It is nominative association. Desk, for example, may bring up the image of chair, student, school and so on. This association is not universal. There are some cultural differences in an association task (Osgood, May and Miron, 1975). When given a word 'cat', people respond to it as it is treated in their own culture. As illustrated in the previous chapter, culture sets limits on language and its use. Metaphors are a part of the culture. An expression like "butter cup" for a pretty woman may not make sense to some people. In Japan a pretty woman may be described as "lily and peony" and in France, "mon petit choe",i.e., "my little cabbage!" Understanding such metaphors requires some cultural knowledge.

\section{(b) Iexical Connotation:Predicate (LC-Predicate)}

This aspect of the lexical connotation is crucial for this study because the LC-Predicate refers to the affective meanings or attitudes, 
and values attached to the word or to the 'argument' of the lexical connotation. Iearning of the LC-Predicate is actually cultural learning which sets up the context for the second language learning process.

Generally, attitude is defined in terms of cognitive, affective, behavioral and social components

(Bem 1970). Cognitive attitude is derived through rational thinking such as syllogistic argument. But some attitudes can be based on totally irrational thinking.

The affective or emotional component of attitude is not cognitive. People are physically and psychologically conditioned in responding to some objects, concepts, or ideas in a certain manner. The process whereby language elicits a particular emotional reaction is called "semantic generalization." The affective component of attitude is evaluative by nature. This is almost equivalent to what we call "gut feelings." It is an intuitive judgment if something is good or bad, or right or wrong, although we cannot tell why.

Attitudes predict or cause behaviors, for example I wear a red sweater because I like it. This behavioral component of attitude causes change in behavior.

The last component is social. The social component of attitude is based on our interactional nature of communication. Social influences create and modify our attitudes and values and vice versa.

All four components are included in the IC-predicate. The response we give towards a word reflects the attitudes and values we hold about the concept the word represents. Two functions of the LC-predicate need to be expounded. 
IC-Predicate: the Appraisal Function

The appraisal function of the IC predicate provides the rationale for using a semantic differential type of questionnaire for this study. "Attitudes function to evaluate 'things' of our experience, setting up at least temporary hypotheses as an aid to understanding reality" (Acton 1979 p. 33).

This function is best explained and illustrated by the semantic Differential Technique (SDT). Osgood et al. (1957) refer to the appraisal function of attitude as the function of affective meaning. The SDT is based on the notion that affective meanings about concepts can be obtained from sets of adjectival scales. These scales consist of three dimensions: evaluation, potency and activity. For each dimension a pair of bipolar adjectives is chosen. Good and bad is a typical pair of evaluation. Strong-weak is typical potency. Active-passive is a pair for activity.

Good

Strong
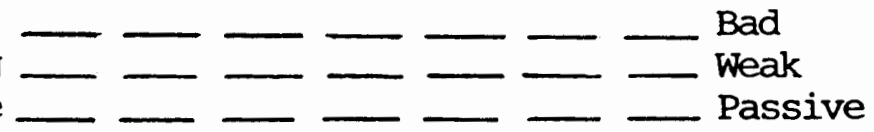

Figure 1. Example of semantic differential technique

The space between the two adjectives reflects the attitudes or affective meanings, which are connotative, assigned to the concept. In other words, the space represents the continua of the domain of affective meanings that subjects hold about concepts symbolized by words.

The importance of the appraisal function of the IC-predicate in second language learning is that it is learned through perception of all kinds of experience. For instance, the answer to the question, "Do 
Americans think automobiles are good or bad?" reflects the learner's own perception of experience with Americans and automobiles. The appraisal function of affective meaning helps the learner to construe the new reality and his new experience in the new culture.

Understanding of affective meaning of concepts in the new culture is accomplished through cultural learning, which is basically done inferentially. These affective meanings are learned not only through language, but also through various channels of senses. Learners who are good at observing this appraisal function of affective meaning of concept are considered sensitive cultural learners, since they are able to differentiate various degree of affective meanings about certain concepts, objects and ideas.

Since these affective meanings are related to values, numerous bits of cultural information are loaded on the inferential, affective meanings. Learning values of the new society is crucial for survival of second language learners. To carry out meaningful conversation, learners must understand the values and affective meanings of concepts represented by words.

Due to the processual and interactional nature of learning, the next function, the social adjustment function of the LC-predicate is even more significant for second language learners.

\section{IC-Predicate: The Social Adjustment Function}

The social adjustment function is the main theoretical foundation for the development of Professed Difference in Attitude Questionnaire (PDAQ) by Acton (1979). The social adjustment function facilitates molding and modification of the conceptual distance. The term 'distance' is, of course, used figuratively. This distance illustrated 
on the scale of the semantic differential technique represents relative affective meanings associated with concepts. Proximity on the scale illustrates similarity, and distance illustrates difference of affective meanings, which is also interpreted as difference in attitudes.

This notion of conceptual distance in affective meanings associated with concepts helps learners identify with a reference group. Reference group refers to the process of grouping. One "is related in some manner to the norms and values shared in that group" (Shibutani 1955 p.562). It provides the frame of reference for the members to compare and evaluate their attitudes and values. It, in short, serves as a "frame of reference" group by providing members with perspectives and world views.

Inmersed into a new cultural group, learners experience distance in attitudes and values from the members of the host culture group, but this distance will be modified in the process of acculturation. At the beginning they identify themselves with none of the host culture groups as reference group. In the process of cultural learning, some learners become closer to the target language culture, and some do not. Closeness is the reflection of similarity in the affective component of attitudes. People who share small conceptual distance in values and attitudes become very similar in their outlook, and they tend to like each other because of the similarity, hence organize a reference group. These modifications of distance between the newcomers and the people in the host culture occur in the process of cultural learning. This process is the function of social adjustment of the IC-predicate. 
(PDAQ) reflects this social adjustment function of the LC-predicate that learners go through in their learning process. PDAQ asks learners about lexical connotation of concepts from three perspectives.

(1) What the subject himself thinks about the concept. (S)

(2) What he thinks his country's people in general think about the concept. (C)

(3) What he thinks Americans think about the concept. (A)

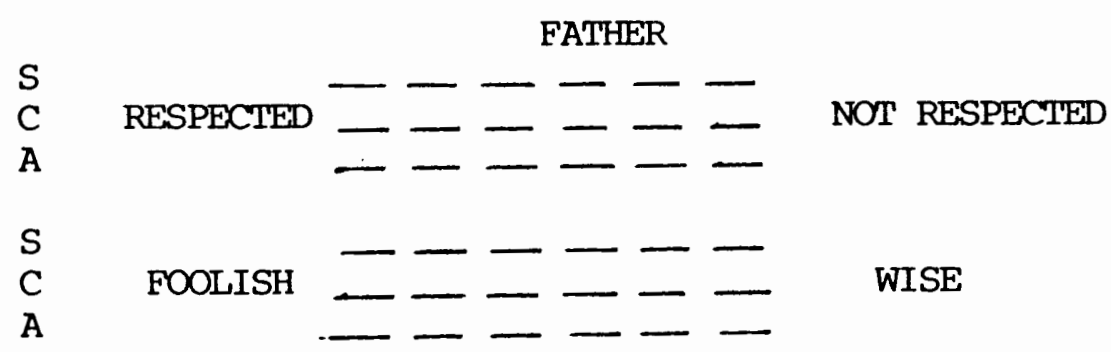

Figure 2. The format of the PDAQ

The space between the two adjectives represents the learner's own attitudes towards concepts. The discrepancy between the marks on S, C, and A dimensions reflects his perception of lexical connotations in two different groups and his own.

The lexical connotation of words serve as a template on which we can observe a subject's (professed) perception of differences in attitudes expressed as distance amongst self, (his) country men, and Americans. (Acton p.40)

The PDAQ portrays the learner's perception of difference in attitudes at one time in the process of acculturation. If a subject's professed difference scores are larger from both cultural groups, we can assume that he is not identifying himself with either one of the groups at that point of time. However, in the process of acculturation it is possible for the same subject to move closer to either one of the groups and eventually share very small distance in perceiving connotation of concepts. The PDAQ reflects learners' changes in 
perception of affective component of connotation.

The distance from both cultures in PDAQ can be interpretea as marginality from either one or both cultural groups. A person who holds very little difference in perceiving affective meanings or attitudes from Americans tends to identify with Americans because of the similarity and likeness, but, at the same time, he is marginal from his country's people due to the large discrepancies in perception of attitudes represented in connotation. However, a person can be marginal from both cultures if he shares very few affective meanings or attitudes from either culture. It is possible to set up an optimal level of marginality, which can be a part of optimal socio-cultural distance that Brown(1980b) proposed.

This marginality from the two groups has a significant role in perception of connotation, which must be reflected in their cultural and language learning. In the next section this vital role of marginality in connection with sensitivity is set forth.

\section{Marginality and Cultural Awareness}

The second language learning situation is actually second culture learning. Since the learner is immersed in the new culture, the "whole person" is involved in "real world" experiences in the new culture (Clarke,1976). This real world experience provides context for second language learning. Since the learner is immersed in the new culture and should live within it, the learning occurs through all kinds of daily experiences. Like other learning, second language learning occurs through the process of experiential learning. In the following sections, marginality is theoretically explained as "cultural awareness", "awareness of the process of doing of culture" by using the 
analogy of Kolb and Fry's experiential learning model and cultural learning process.

According to Kolb and Fry(1979), experiential learning takes place in four stages; 1) Concrete Experience, 2) Observation and Reflection, 3)Formation of Abstract Concepts and Generalization, and 4) Testing implication of Concepts in New Situations. None of the stages can be omitted if the learning is to be effective and successful. In each stage, different skills are applied; concrete experience(CE) skills, reflective observation(RO) skills, abstract conceptualization(AC) skills and active experiential (AE) skills.

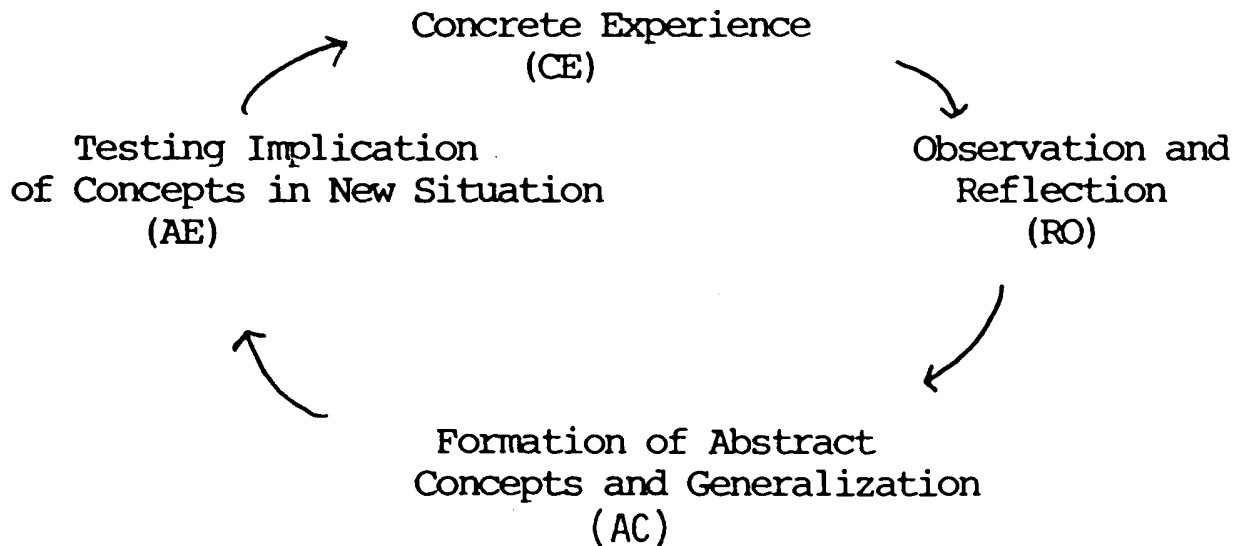

Fiqure 3. The experiential learning model

Not all learners are necessarily equipped with all four skills. Each learner has his own strengths and weaknesses, yet for effective and successful learning, all four skills are needed to some extent. Among these four skills, Reflective Observation and Abstract Conceptualization are the skills that develop the most awareness of the process.

The reflective observation skills enable the learner to reflect 
upon concrete experience from different perspectives, and abstract conceptualization skills enable the learner to conceptualize and integrate these observations in some abstract, generalized forms. The $\checkmark$ reflective observation skills are best used in a perceptually oriented environment, and abstract conceptualization skills in a symbolically oriented environment. These two kinds of skills are most useful in learning connotative meanings in language, because they are implied in symbols. These two skills enable a learner to observe and analyze the second language objectively. For example, the word "censorship" is presented as symbol, but its connotation or affective meaning is presented only inferentially as part of the whole communicated meaning. Therefore, a learner should be able to perceive, analyze and generalize the inferred meaning of "censorship" so that he can use it, or at least understand it more fully.

The Reflective Observation skills enhance the awareness of the process in which the learner is involved. He can obtain this awareness at the price of marginality from the society. The process of setting oneself aside from concrete experience fosters awareness of the process of unconscious everyday practice in the society. This is parallel to Mead's (1934) notion of "Me" who observes reflectively the behavior of "I" who is in action and unconscious of this action. The learner who is well equipped with reflective observation skills can detach himself from the concrete experience and his conceptual, cognitive learning process. In cultural learning, if the learner is very observant and analytical of the cultural behaviors, he becomes marginal, in some degree, from either or both his own cultural groups and the target language cultural group. It is similar to the situation where one can 
observe and analyze a chess game better when he is observing the game by the table rather than playing.

Stern (1980) counts the above awareness as one of the strategies for good language learners; awareness of the underlying sociocultural meanings and connotations of language. Good language learners observe the language in use with reflective thinking, elicit some meaning and integrate it with generalized meanings.

"Awareness in one's own language use" is another strategy that good learners use. According to Stern, this awareness manifests itself as self-monitoring and critical sensitivity to language use. Self-monitoring has a significant impact on second language learning. The Monitor model for adult second language learning was proposed by Krashen $(1976,1980)$. He illustrated two different types of learning processes. One is conscious learning, where the learner consciously monitors his language usage. The other is the subconscious process, which is equated with children's first language acquisition process, in which the learner only feels if his language usage is right or wrong, but does not monitor it.

Conscious learning plays a more vital role in adult second language learning than in a child's. By the age of twelve, children develop the ability to think abstractly and to deal with abstract constructs as if they were objects (Inhelder and Piaget, 1958). Krashen (1980) notes that conscious learning is directly related to language aptitude for adult second language learning.

The whole process can be explained by Bennett's (1977) Forming and Feeling model. For the beginning language and culture learner, all the communication processes are intensive because they need extreme 
effort to keep communication from breaking down. In such a context, the learner becomes aware of his utterances, trying to be correct in order to communicate what he wants to. This process requires a conscious meta-awareness and as much as possible control of verbal and nonverbal behaviors. However, once the learner has internalized appropriate forms of language and behavior for a particular context, he only feels if his "form", which is his expression, is right or wrong and would not go back to the meta-awareness level unless he feels the need for change. When monitoring, like editing one's own writing, it is necessary to be able to use meta-awareness so that one can perceive the grammatical rules and lexical choices with more control. In conversation, this meta-level perception is useful not only for observing lexical and grammatical rules, but also for analyzing the appropriateness of non-linguistic behavior in context. This using of meta-awareness is the detachment of self from the on going process of experience. This is the state of marginality to a communication event.

If a person can observe the process of communication reflectively, in which he is also involved, he cannot be in the center of the process. He is marginal from that process and the group of people, by virtue of his ability to see them as if they were something observable from a distance.

This marginality is the basis for providing the skills to develop more sensitivity which is inherent to a bicultural person. Marginality and sensitivity are complementary. Bieri(1955) points out this phenomenon with different terminology. Sensitivity and marginality are quantitative differentiation and qualitative differentiation respectively. He says, in communication, both quantitative and 
qualitative differences are important to recognize. Quantitative cognitive complexity increases the possibility of responding to other's behavior in various ways. However, if a person "reacts to an insignificant gesture with an elaborate delusional structure, his complex reaction is considered inappropriate to the objectively simple gesture" (Bieri, p.267). This indicates the lack of qualitative differentiation. In second culture and language learning, quantitative complexity enhances sensitivity rather than awareness; it enables a person to respond to various situations from various perspectives. Qualitative complexity enhances awareness; it enables a person to respond to reality with more accuracy so that his perception, interpretation, and behavior can be more appropriate.

Marginality certainly enhances and promotes sensitivity; much of the literature supports this concept. Long ago, Everett V. Stonequist (1935) described a marginal man as a man with increased sensitivity and self-consciousness. Applying Cooley's looking-glass theory, Stonequist made an analogy between a man becoming a marginal man and a man standing between two looking glasses and watching his various images in the mirrors. Sensitivity and awareness are, thus, complementary. For more effective, successful language learning, learners should implement both. In the next chapter, the significance of sensitivity, that is typified as biculturality, and marginality in relation with second language learning is formed into three major hypotheses. 
RESEARCH DESIGN

This is a descriptive study of the relationship between cultural learning and second language learning. This study is based on the findings of William Acton, the developer of the Professed Difference in Attitude Questionnaire, which is used for this study. Acton's study was developed from a linguistic point of view, but his research findings of socio-cultural equidistance in relative analysis gave impetus to pursue this topic from an intercultural communication point of view.

\section{Research Questions}

1. Is biculturality an optimal socio-cultural distance for successful second language learning?

2. How does marginality from the native and the target language culture respectively relate to second language learning?

3. Is the length of residence in the new culture associated with socio-cultural distance?

Three hypotheses are derived from these research questions respectively.

\section{Research Hypotheses}

Hypothesis 1. There is a positive association between biculturality and second language proficiency.

Hypothesis 2. There is a positive association between socio-cultural marginality and second language proficiency.

Hypothesis 3. Subjects who have been in the U.S. more than six months 
are more bicultural than those who have been in the U.S. less than six months.

\section{Definitions}

This study deals with second language learning by adult learners in second language culture, which is the U.S.A. Therefore, the subjects' target language is English whereas the native language and culture vary. The instruments used in this study are the Professed Difference in Attitude Questionnaire (PDAQ) (Acton,1979) and the Michigan Test of English Language Proficiency (1979). The PDAQ measures socio-cultural distance, which is a figurative distance manifested as differences on scores of semantic differential type of questionnaire on perception of connotation. Language proficiency is measured by the Michigan Test. The scores obtained from both instruments are used as data to assess the association between language proficiency and socio-cultural distance. A detailed description of each instrument will be given in the section of "instruments".

\section{Design of the Study}

The research design consists of three parts. First, it was necessary to establish the reliability of the questionnaire by test-retest method. Second, after establishing the reliability, the questionnaire was administered to international students at Portland State University and Lewis and Clark College. Third, the obtained data were analyzed.

\section{Instruments}

Professed Difference in Attitude Questionnaire (PDAQ)

The PDAQ measures socio-cultural difference through the 
perception of lexical connotation. It does not measure the direct personal attitude toward the target culture. For example, it does not ask questions such as "Do you think Americans are, very well, somewhat, average, only a little, or not at all, friendly?" This would be like asking about their stereotypes of Americans. The PDAQ measures more indirect, subtle aspects of cultural learning. It asks the subject's perception of American's perception, his countrymen's perception, and his own perception on certain concepts. The PDAQ consists of two sets of three semantic differentials for each concept as illustrated in Figure 4. There are twenty concepts in the whole questionnaire (appendix B) •

key: S=Self (Subject's professed personal attitude) $\mathrm{C}=$ Countrymen (Subject's assessment of the attitudes of the general populace in his native country/culture) $\mathrm{A}=$ Americans (Subject's assessment of American attitudes on the same item.)

S

A NOT VALUABLE

TEIEVISION

$S$

C

C HONEST
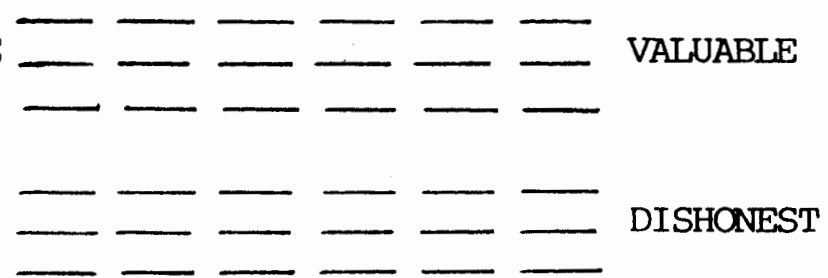

THE UNITED STATES

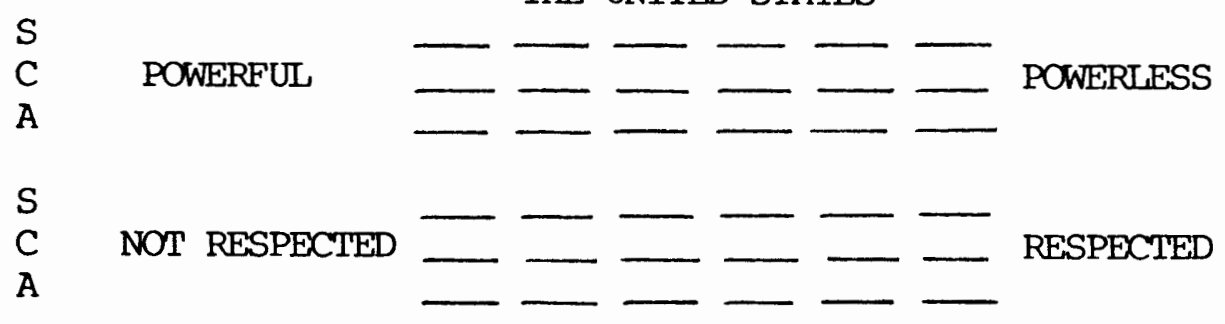

Fiqure 4. Example of the PDAQ questionnaire

These two sets of adjectives for each concept are chosen "primarily on the basis of which elicited the most 'distance'" (Acton 
p.75). Unlike the standard semantic differential format, the PDAQ has six spaces between the two adjectives. Although Osgood et al. (1975) recommend seven spaces, Acton uses six spaces in order to deprive subjects of the mid-point, forcing more discriminations.

\section{The Michigan Test}

In Acton's original study, the Michigan Test Battery was used; however, due to the difficulty in obtaining the full battery score, the Michigan Test score, which is a part of the Michigan Test Battery was used for this study. The Michigan Test Battery is composed of grammar, vocabulary, aural comprehension, reading comprehension and some type of test of writing ability. The Michigan Test does not include aural comprehension and a test of writing ability. Despite the lack of these two components, the correlation between the Michigan Test and the Michigan Test Battery is significant as shown in table 1. This helps to establish the validity of the Michigan test as a measurement tool for the present study.

TABLE I

CORREILATION BETWEEN MICHIGAN TEST AND MICHIGAN BATTERY

\begin{tabular}{|c|c|c|c|c|c|}
\hline & Michigan & Battery & Michigan & Test & \\
\hline $\mathrm{N}$ & M & SD & M & SD & $r$ \\
\hline & 72.44 & 8.3 & $57.5 a$ & $14.6 \mathrm{a}$ & 84 \\
\hline
\end{tabular}

Raw scores

(From the manual of Michigan Test p.18)

The coefficients of correlation between the Michigan Test and TOEFL (Test Of English as a Foreign Language), which includes aural comprehension, is also very high as illustrated in table 2. These high correlation coefficients again support validity of the Michigan test 
and they support its use as single indicator of language proficiency.

\section{TABLE II}

CORREILATION BETWEEN TOEFL AND MICHIGAN TEST

$\begin{array}{lrllcccl} & & \text { TOEFL } & & \text { MT-C } & & \text { OBTAINED } & \text { ESTIMATED } \\ \text { SAMPLE } & \text { N } & \text { MEAN } & \text { SD } & \text { MEAN } & \text { SD } & \text { R } & \mathrm{R}^{\prime} \text { a } \\ \text { L.S.U. } & 29 & 420.4 & 56.9 & 54.5 & 15.3 & .834 & .914 \\ \text { Indiana } & 38 & 390.6 & 61.7 & 50.1 & 14.4 & .899 & .943 \\ \text { San Francisco } & 50 & 382.2 & 58.4 & 51.6 & 13.7 & .865 & .929 \\ \text { New York } & 108 & 383.0 & 47.8 & 47.2 & 13.1 & .803 & .923 \\ \text { Total } & 225 & 388.7 & 56.6 & 49.6 & 14.0 & .881 & .942\end{array}$

A Estimated correlation between TOEFL and MT-C for uncurtailed range of TOEFL. Uncurtailed S.D. is 85.

(from the manual of Michigan Test p.19)

\section{Reliability Study of the PDAQ}

A reliability study on the PDAQ was done since the original study by Acton(1979) does not have the information on the reliability of the questionnaire. Fourteen complete data sets were used for assessing reliability. All subjects were advanced students who were registered in level four at the Center for English as a Second Language at Portland State University. The PDAQ was administered twice at two week intervals.

Based on the PDAQ, three difference scores were calculated representing the distance between self and countrymen (S-C), Americans and self $(A-S)$, and countrymen and Americans (C-A). The Pearson Product Moment Coefficient was used to analyze the data. The guideline is taken from Guilford (1956) .

*.00 to .20 slight, almost negligible relationship

*.20 to .40 low correlation, definite but small relationship

*.40 to .70 moderate correlation, substantial relationship 
*.70 to .90 high correlation, marked relationship

*.90 and up very high correlation, very dependable relationship

TABIE III

RESULT OF RELIABILITY TESTING ON THE PDAQ

Mean $X \quad$ Mean $Y$ SDX SDY Corr.

$\begin{array}{llllll}\text { S-C } & 25.21 & 26.21 & 11.76 & 15.78 & 0.78 \\ \text { C-A } & 47.50 & 46.00 & 17.74 & 19.46 & 0.86 \\ \text { A-S } & 41.28 & 37.71 & 16.57 & 12.12 & 0.76\end{array}$

$\mathrm{n}=14, \mathrm{p}<.001$

key $\mathrm{SD}=$ standard deviation

Based on Guilford's(1956) guideline for strength of association, - "high" correlation was obtained for all three distance scores from test-retest data.

The PDAQ Administration

\section{Operational Hypotheses}

1. The correlation between biculturality as defined by closeness to equidistance position derived from the Professed Distance Attitude Questionnaire (PDAQ) and second language proficiency as measured by the Michigan test will be positive and significant.

2. The correlation between marginality as defined by the height position derived from the PDAQ and second language proficiency as measured by the Michigan test will be positive and significant.

3. The group of subjects who have been in the U.S. for more than six months will display significantly higher biculturality as defined by closeness to equidistance derived from the PDAQ than the group of subjects who have been in the U.S. for less than six months.

\section{Subjects}

Subsequent to the reliability study, PDAQ was administered to 77 international students who were enrolled in an intensive English language course at Portland State University or Lewis and Clark 
College. The primary criterion for selecting subjects was that they should be in the upper level of the intensive program so that they have enough vocabulary to take the PDAQ in English. Of the 77 responses, 5 were incomplete and 7 were not provided with the Michigan Test scores. As a result, a total of 65 were used for analysis. Distribution of subjects by native languages is given in Table 4 .

TABLE IV

DISTRIBUTION OF SUBJECTS BY NATIVE LANGUAGES

$\begin{array}{lrlr}\text { Japanese } & 22 & \text { Chinese } & 12 \\ \text { Indonesian } & 4 & \text { Arabic } & 6 \\ \text { Spanish } & 3 & \text { Portuguese } & 3 \\ \text { Korean } & 3 & \text { Others } & 9 \\ \text { Farsi } & 3 & & \end{array}$

Procedures

All the PDAQs, together with demographic questionnaires, were administered by the researcher during class periods. All the responses were collected after the class period. Within a month, each subject's score on the Michigan Test was obtained through the office of the Center for English as a Second Language at Portland State University and the American Language Institute at Lewis and Clark College. Copies of the PDAQ, demographic questionnaire, cover letter, and the instructions are in appendix $\mathrm{A}$.

\section{Measurement Procedure}

The study used the correlational technique with the PDAQ scores on the Michigan test scores. Since this study attempted to find socio-cultural differences in perception of connotation, it utilized difference scores between the marks on three dimensions. As illustrated in figure 8, the spaces between each marks are counted. Figure 8 counts 
$S C=2, \quad C A=2, \quad A S=4$. The total of these scores on twenty concepts will be tabulated.

TELEVISION

$S$

C NOT VALUABLE $-\frac{x}{-}-\frac{x}{-}-\frac{}{x}$

VALUABLE

Figure 5. Scoring three distance scores on PDAQ

The total scores of these three distance scores were formulated into a triangle as shown in figure, 9. The figure represents a triangle of total scores, $\mathrm{SC}=14, \mathrm{CA}=37$, and $\mathrm{AS}=33$.

$\mathrm{SC}=14$

$\mathrm{CA}=37$

$\mathrm{AS}=33$

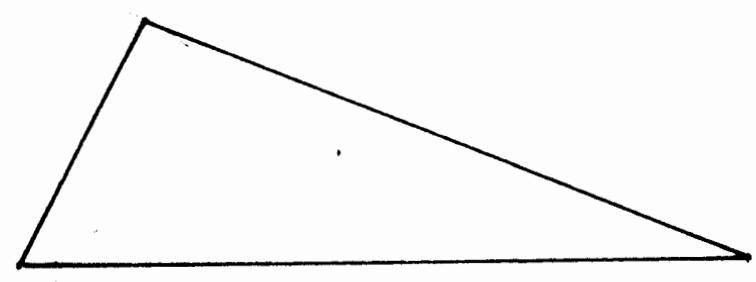

Figure 6. Example of the triangle Model based on PDAQ scores

It is important to note that there are cultural differences in the expression of perception of connotation as measured on this test. It was necessary to minimize such differences. Since the main concern is assessment of each individual's socio-cultural relationship in terms of two cultures, American and native, scores around the "self", i.e. SC and AS were allotted to the distance between the countrymen and American (AC). This process manifests the socio-cultural position of the self based on the perceived general cultural differences. The allotted scores of figure 9 will be shown in figure 10. The distance from the middle point of American and the Countrymen was hypothesized 
as the optimal bicultural point " $M$ ". The distance from the point " $M$ " and the $\mathrm{D}$ of the SD drawn perpendicularly from $\mathrm{S}$ to the bottom line was calculated as "d". The altitude SD, "h", was, hypothesized as marginality.

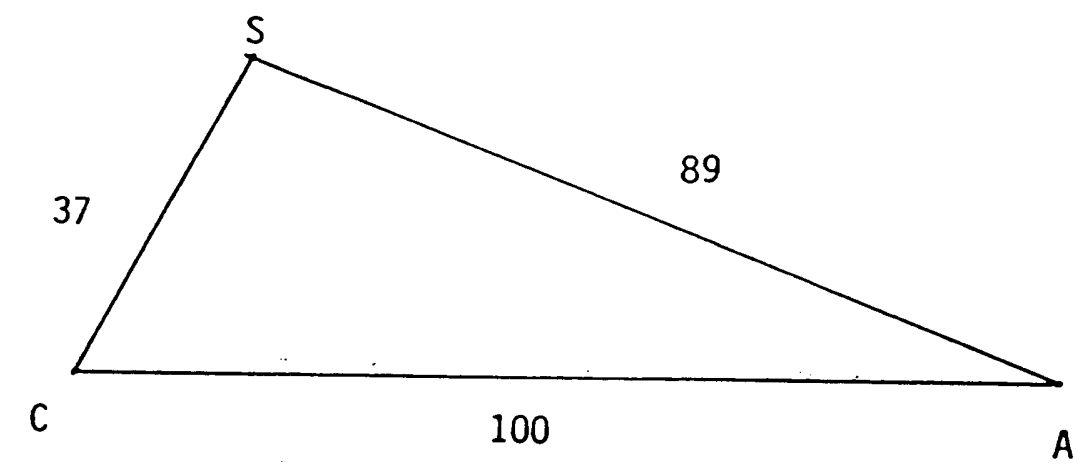

Figure 7. Triangle of the allotted scores of figure 6 .

Scores between the Self, Countrymen, and Americans, and allotted scores between the Self and Countrymen (SC) and Self and Americans (SA), the distance from the middle point (d) and the altitude (h) were assessed to find the association with the Michigan Test scores by using the Pearson product-moment correlation coefficient.

A significance level of .05 was set to utilize the data score and the significance of correlation coefficients was based on the guideline given by Guilford (1956) (see page 50). 


\section{CHAPTER V}

\section{RESULTS}

This chapter presents the results of the research and a discussion of the analyzed data. First, the results of the correlational analysis are presented and then, the data are analyzed for trends. In this discussion the interpretation of biculturality and marginality are reconsidered. Three hypotheses were tested. They were: Hypothesis 1. There is a positive association between biculturality and second language proficiency.

Hypothesis 2. There is a positive association between socio-cultural marginality from the two cultures and second language proficiency.

Hypothesis 3. Subjects who have been in the U.S. more than six months are more bicultural than those who have been in the U.S. less than six months.

The abbreviated symbols used in this chapter are illustrated in figure 8.

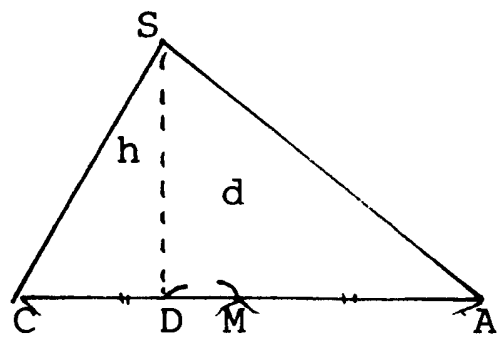

Figure 8. Triangular representation and abbreviated symbols

Each symbol stands for the following meaning;

$S=t o t a l$ score on Self in PDAQ

$\mathrm{C}=$ total score on Countrymen in general in PDAQ 
A =total score on Americans in PDAQ

$\mathrm{M}=$ Midpoint between Countrymen and Americans

$D=$ the intersection of the segment from the vertex $S$

$\mathrm{d}=$ Distance from the midpoint $\mathrm{M}$ (biculturality score)

$\mathrm{h}=$ Height (marginality score)

\section{Hypothesis Testing Results}

Hypothesis 1. There is a positive association between biculturality and second language proficiency.

The association between biculturality and language proficiency was not found to be significant (.05 or higher). This correlation is stated in the "d" column.

TABLE V

RESULTS OF CORREIATIONAL ANALYSIS

OF PDAQ SCORES ON THE MICHIGAN TEST SCORES

\begin{tabular}{|c|c|c|c|c|c|}
\hline & & SC & AS & d & $\stackrel{\mathrm{h}}{-0.0012}$ \\
\hline $\mathrm{N}=65$ & $r$ & 0.0152 & -0.0102 & 0.0144 & -0.0012 \\
\hline $\mathrm{MT}=73$ & $\begin{array}{l}\text { MEAN } \\
\text { SD }\end{array}$ & $\begin{array}{l}57.6 \\
28.2\end{array}$ & $\begin{array}{l}90.6 \\
20.4\end{array}$ & $\begin{array}{l}27.1 \\
17.4\end{array}$ & $\begin{array}{l}47.1 \\
25.7\end{array}$ \\
\hline
\end{tabular}

Since none of the scores was found to be significant, trend analysis was done to determine if a pattern of any kind was present in the data. In order to do this trend analysis, subjects were divided into three groups based on their Michigan Test scores. Fach group was examined if there is any significant correlation with the Michigan Test and the PDAQ within the group.

TABLE VI

SUBJECT DISTRIBUTION BASED ON THE MICHIGAN TEST SCORE

NOS MEAN S.D.

HIGH

MIDDLE

LOW
17

23

25
83

74

65
3.5

1.7

3.2 
TABLE VII

RESULTS OF TREND ANALYSIS: CORRELATION

$\mathrm{OF}$

THE PDAQ SCORES ON THE MICHIGAN TEST SCORES

\begin{tabular}{|c|c|c|c|c|c|}
\hline & & SC & AS & $\mathrm{d}$ & $\mathrm{h}$ \\
\hline $\begin{array}{l}\mathrm{HIGH} \\
\mathrm{N}=17 \\
\mathrm{MT}=83\end{array}$ & $\begin{array}{l}\mathrm{r} \\
\mathrm{M} \\
\mathrm{SD}\end{array}$ & $\begin{array}{c}0.1262 \\
53.6 \\
(37.3)\end{array}$ & $\begin{array}{c}0.0083 \\
91.0 \\
(27.3)\end{array}$ & $\begin{array}{c}-0.1847 \\
31.1 \\
(15.6)\end{array}$ & $\begin{array}{c}0.0677 \\
44.5 \\
(35.1)\end{array}$ \\
\hline $\begin{array}{l}\text { Middle } \\
\mathrm{N}=23 \\
\mathrm{MT}=74\end{array}$ & $\begin{array}{l}\mathrm{r} \\
\mathrm{M} \\
\mathrm{SD}\end{array}$ & $\begin{array}{r}-0.0774 \\
64.1 \\
(22.5)\end{array}$ & $\begin{array}{c}0.3302 \\
82.1 \\
(21.6)\end{array}$ & $\begin{array}{c}0.4643^{*} \\
21.5 \\
(15.6)\end{array}$ & $\begin{array}{c}0.0667 \\
48.2 \\
(19.7)\end{array}$ \\
\hline $\begin{array}{l}\text { Low } \\
N=25 \\
M T=65\end{array}$ & $\begin{array}{l}r \\
M \\
S D\end{array}$ & $\begin{array}{r}-0.0594 \\
54.2 \\
(25.9)\end{array}$ & $\begin{array}{r}-0.1991 \\
94.7 \\
(19.0)\end{array}$ & $\begin{array}{c}-0.1735 \\
29.0 \\
(20.0)\end{array}$ & $\begin{array}{c}-0.0521 \\
46.9 \\
(25.4)\end{array}$ \\
\hline
\end{tabular}

No significant correlation was found in regard to the scores on "d" (biculturality score). In this analysis, only group "Middle" displayed moderate correlation between the Michigan test scores and " $\mathrm{h}$ " scores.

These results contradicted William Acton's original study. His research found a smaller " $d$ " than the present study ( Note that in Acton's study, the equivalent of " $\mathrm{d}$ " is distance from $\mathrm{x}=\mathrm{y}$ axis). The peculiar phenomenon in the present study was that groups "HIGH" and "LOW" had some common patterns. This was more obvious when these scores were put on scatter plots, similar ones used in Acton's study. (Figure 9, 10, and 11). The pattern manifested by the group "MIDDLE" was what had been expected for the group "HIGH" based on Acton's study. 


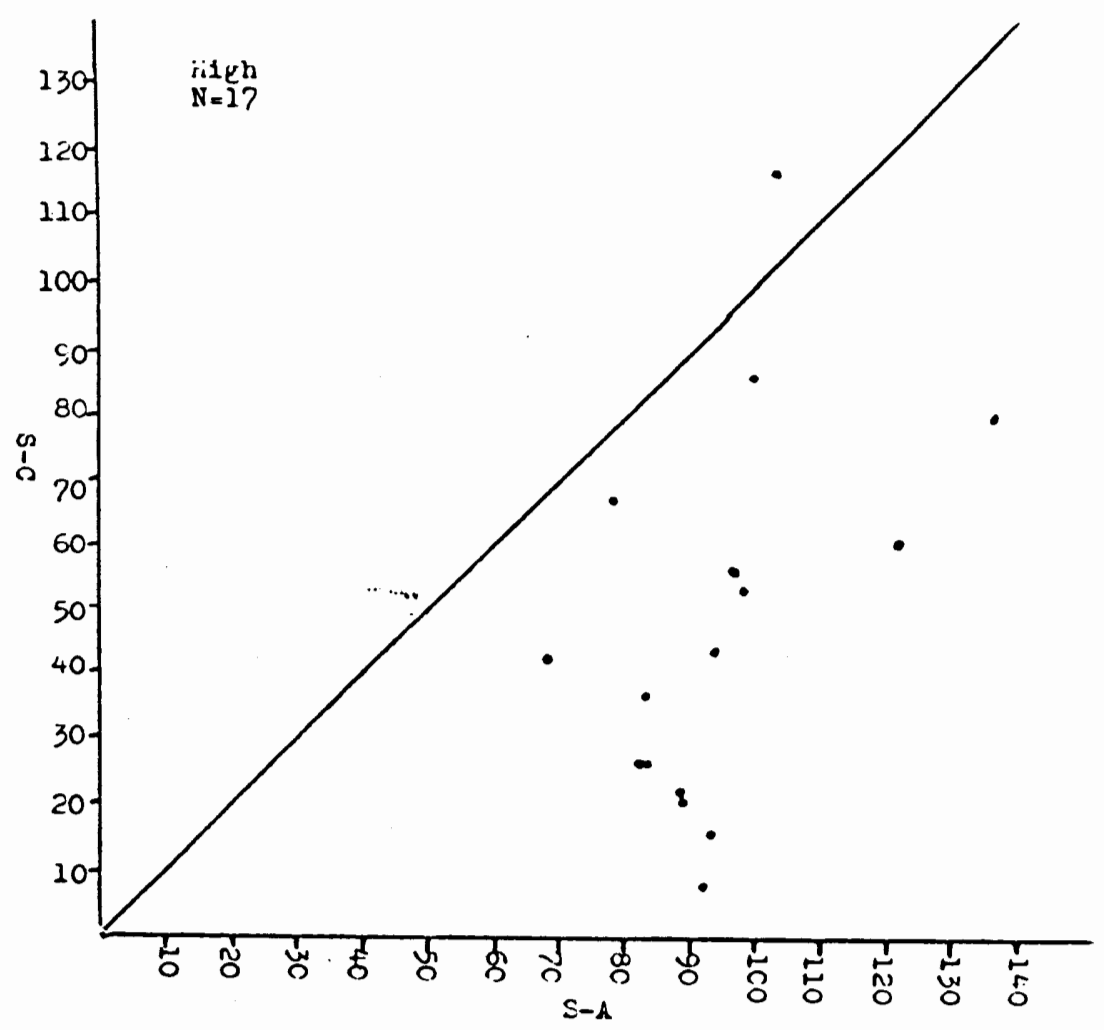

Figure 9. Scatter plots for group HIGH

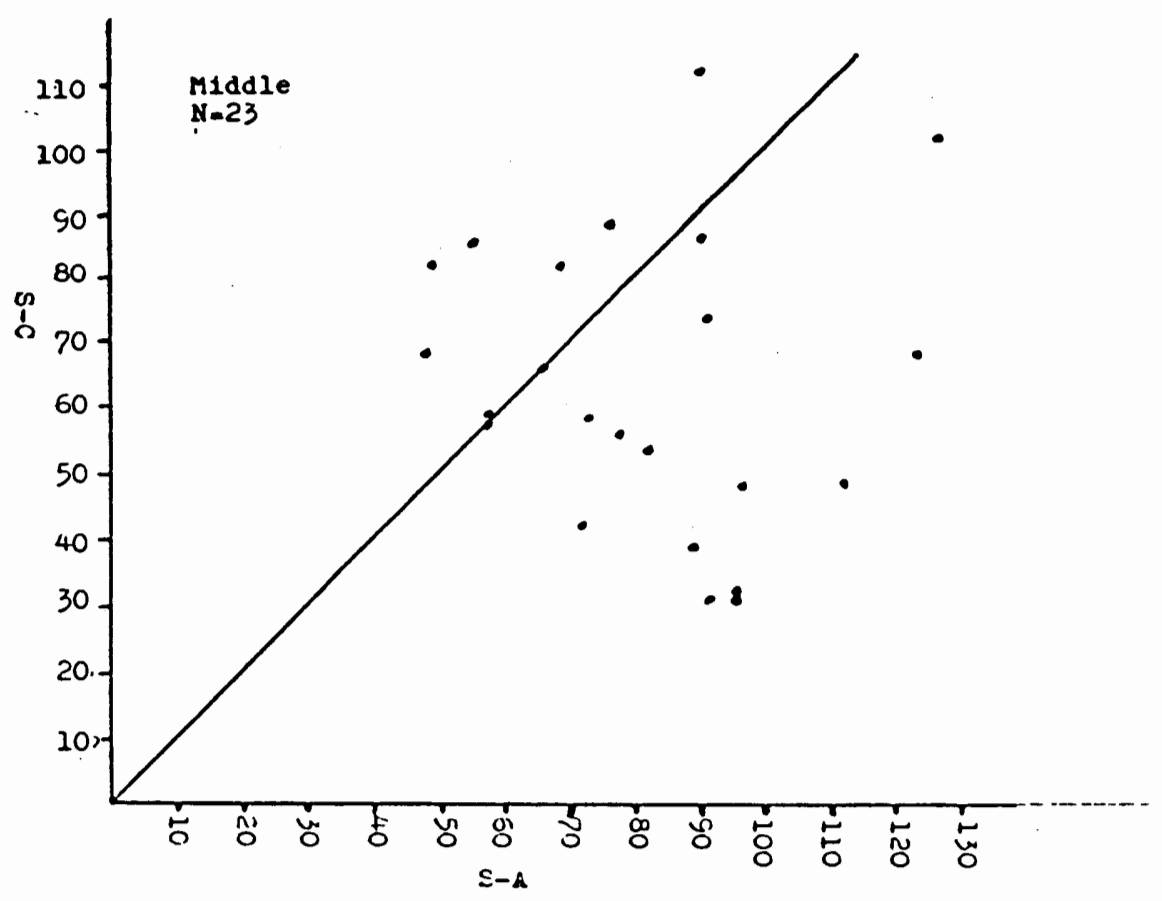

Figure 10. Scatter plots for group MIDDLE 


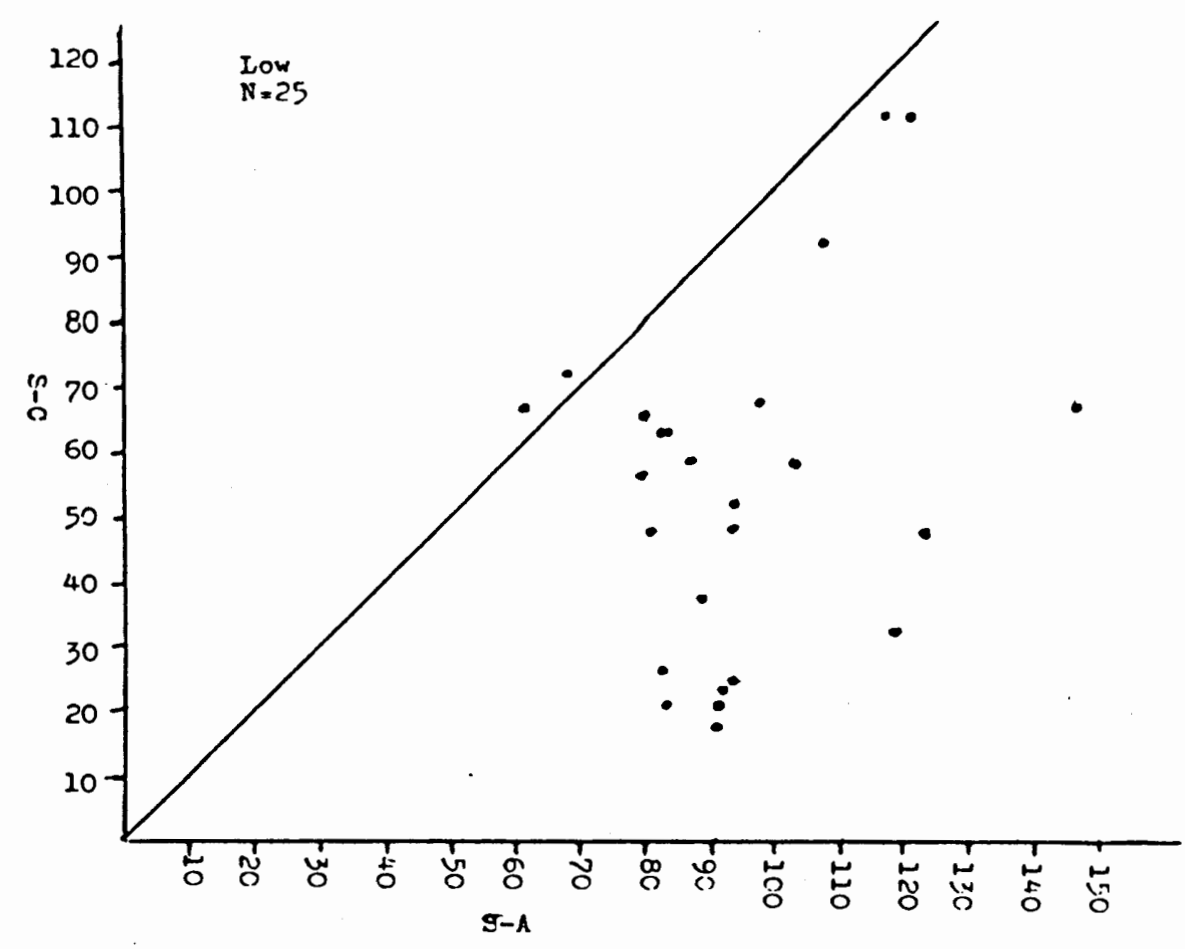

Figure 11. Scatter plots for group Low

The triangular representations are shown in figures 12, 13, and 14. The scores between the Self and Americans (AS), and the Self and countrymen (SC) are allotted by the score of Americans and Countrymen (AC) in order to minimize the cultural difference in the expression of perception of lexical connotation.

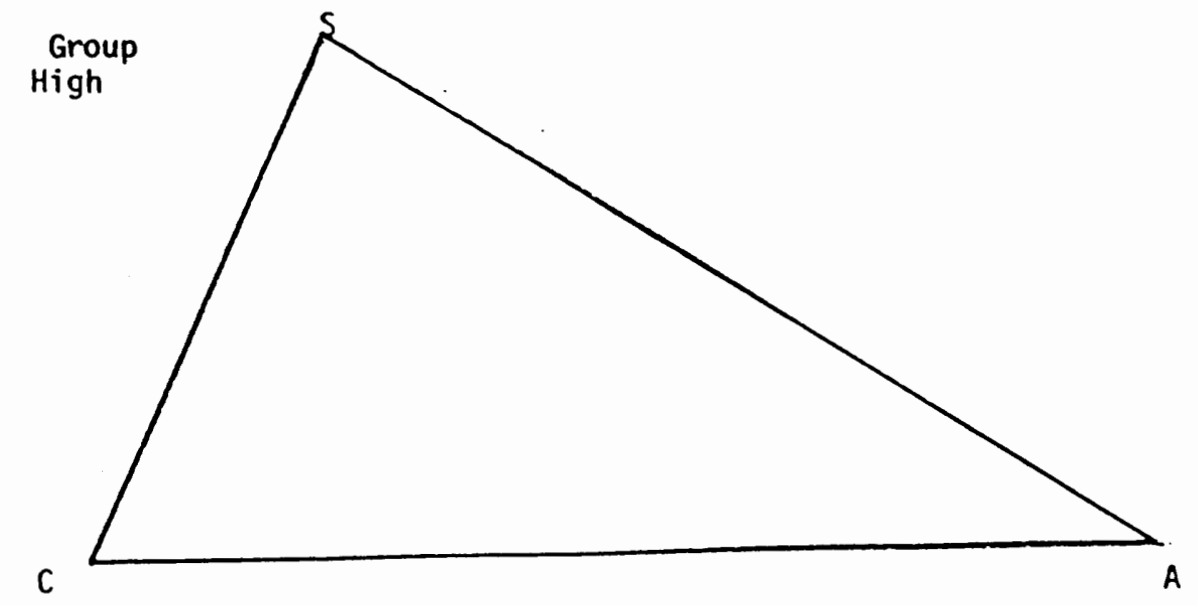

Figure 12. Triangular representation for group HIGH 


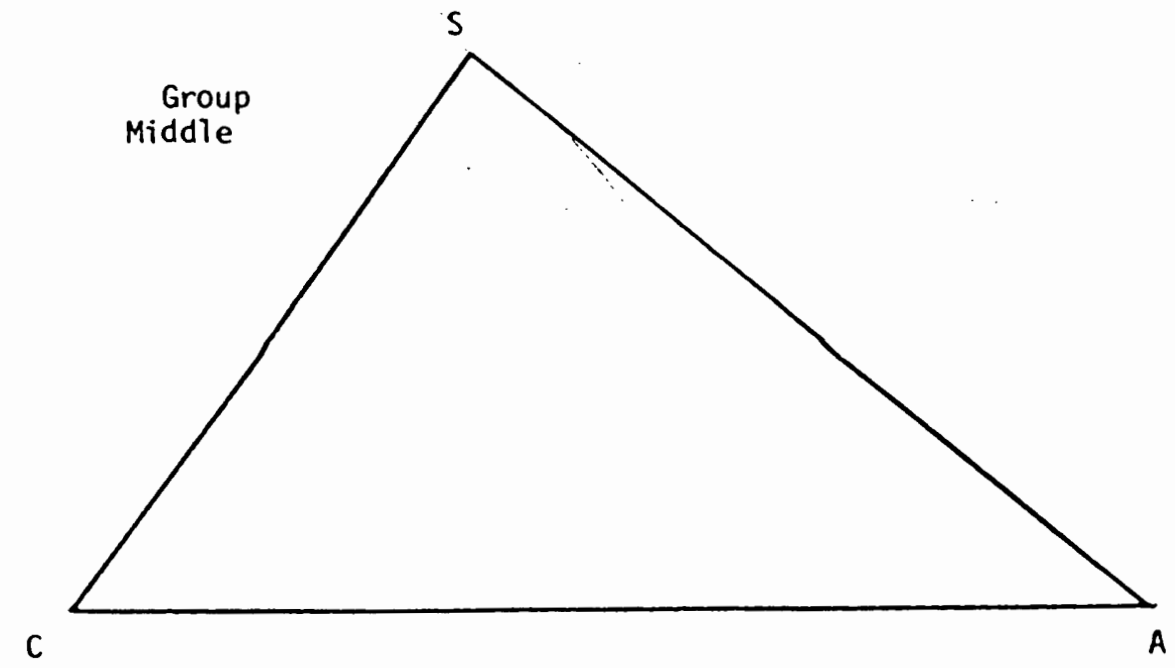

Figure 13. Triangular representation for group MIDDLE

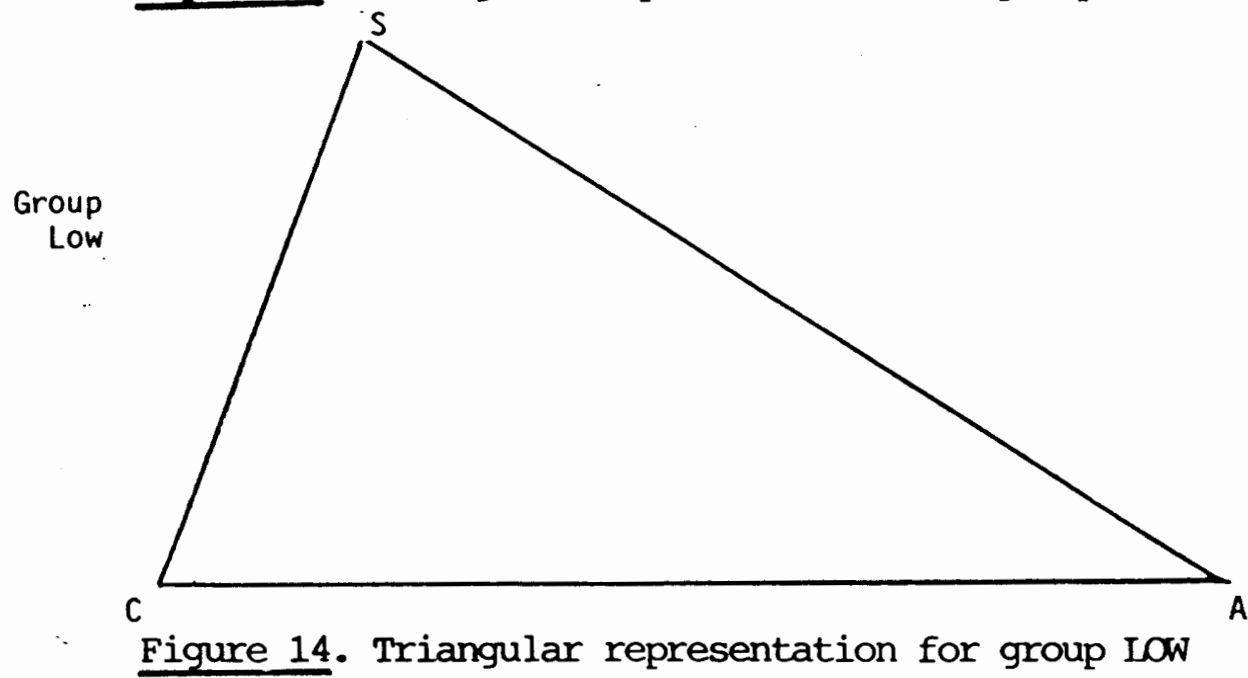

Again it should be noted that none of these data was significant; the "middle" group showed somewhat greater tendency towards the bicultural equidistance point than the "high" group, contradicting to the hypothesis.

Hypothesis 2. There is a positive association between socio-cultural marginality from the two cultures and second language proficiency.

There was no positive association between the marginality scores of the PDAQ and the language proficiency scores. The results is illustrated in table $\mathrm{V}$ (" $\mathrm{h}$ " column) on page 56. A secondary analysis of groups, following the same procedure as that of the trend analysis 
for hypothesis 1, did not show any consistent direction either. (See table VII, "h" colum, on page 52 )

Hypothesis 3. Subjects who have been in the U.S. more than six months are more bicultural than those who have been here less than six months.

Subjects were divided into two groups based on the length of residence in the U.S. The border line of six months is the shortest period of time that allows sufficient numbers of subjects for a group.

There are 23 subjects who have been in the U. S. for less than six months, and 42 subjects for more than six months. The mean scores and standard deviation are illustrated in table VIII.

TABLE VIII

CONTRAST BETWEEN "MORE THAN 6 MO."

AND

"LESS THAN 6 MO." BY MEAN PDAQ SCORES

$\begin{array}{lcccccc} & & \text { MT } & \text { SC } & \text { AS } & \text { D } & \text { H } \\ \text { MORE THAN } & \text { MEAN } & 70.0 & 56.7 & 96.8 & 31.1 & 49.1 \\ 6 \text { MO. } & \text { SD } & 7.0 & 28.6 & 18.9 & 18.5 & 26.8 \\ & & & & & & \\ \text { LESS THAN } & \text { MEAN } & 79.0 & 58.9 & 79.2 & 20.1 & 46.7 \\ 6 \text { MO. } & \text { SD } & 6.5 & 28.7 & 18.6 & 12.8 & 27.2\end{array}$

The above data indicate that subjects who have stayed in the U. S. more than six months have larger " $d$ " scores than subjects who have stayed in the U.S less than six months. This is the reverse direction from the hypothesis. Hence, no $\mathrm{T}$ test was done to establish significance of the long term and short term difference in biculturality.

In the above analysis, language proficiency was not considered in dividing groups of "More than 6 Mo." and "Less than 6 Mo." It was questioned that if the language proficiency level was controlled, and only subjects who are different in length of resident (LOR) were 
compared, how the biculturality score "d" would be different. In order to control the language proficiency level, the group "more than six mo." was divided into two based on the Michigan test scores. Since the group of "Less than Six mo. with High proficiency (LSH)" consists of subjects who obtained 70 and up on the Michigan Test, the subject with the same proficiency level were sorted out from the group of "More than Six mo. with High proficiency (MSH)." These are 23 subjects who obtained the average scores of 76 on the Michigan test (MT). The rest of the subjects who form a group of lower proficiency level (average MT scores of 64) are put under the group of "More than Six mo. with Low proficiency (MSL)."

TABLE IX

DISTRIBUTION OF SUBJECTS BASED ON LOR AND MT SCORES MT MEAN SCORES SUBJECTS

LSH 79 22

MSH 76 23

MSL 64 19

The correlational analysis between the PDAQ scores and MT scores was done. The results are listed below in table $\mathrm{x}$.

\section{TABLE $\mathrm{X}$}

PDAQ MEAN SCORES FOR THREE GROUPS

\begin{tabular}{llcccc} 
& & CS & AS & d & h \\
LSH & MEAN & 58.9 & 79.2 & 20.1 & 46.7 \\
& SD & $(28.7)$ & $(18.6)$ & $(12.8)$ & $(27.2)$ \\
& & & & & \\
\multirow{2}{*}{ MSH } & MEAN & 61.0 & 97.9 & 30.6 & 53.8 \\
& SD & $(30.5)$ & $(18.1)$ & $(15.7)$ & $(28.6)$ \\
& & & & & \\
MSL & MEAN & 51.5 & 95.4 & 31.6 & 43.5 \\
& SD & $(26.1)$ & $(20.4)$ & $(21.9)$ & $(24.1)$
\end{tabular}


*ISH N=22 Length of Residence (LOR) is less than six months; the Michigan test score is higher than 70 .

*MSH $\mathrm{N}=23$ LOR is more than six months; the Michigan test score is higher than 70 .

*MSL N=19 LOR is more than six months; the Michigan test score is lower than 69 .

A conspicuous difference is observed between the groups ISH and MSH on AS and "d". The scores on "d" (biculturality) seem to be the function of "AS", the distance between the "Self" and "Americans". Subjects who have been in the U.S. less than 6 months tend to demonstrate smaller distance scores from the Americans compared to the other two groups. Furthermore, they demonstrate small " $d$ " scores from the equidistant point of the two cultures (table VIII and figure 9). The comparison between ISH and MSH suggests that length of residence in the host country does not develop more biculturality as expected. This result does not support the hypothesis, and contradicts results from many similar kinds of research including Acton's study. The MSL group manifests the most ethnocentric socio-cultural distance, being close to their own culture and distant from the target language culture. (table VIII and figure 17)

The scatter plots of these three groups are shown in figures 18 to 20. The LSH group (figure 18) demonstrates a very similar pattern to the "Middle" group (the group based on the MT scores), in terms of biculturality, being closer to the $x=y$ axis ( see figure 10 on page ). This is contradictory to expected result from the hypothesis 3. 


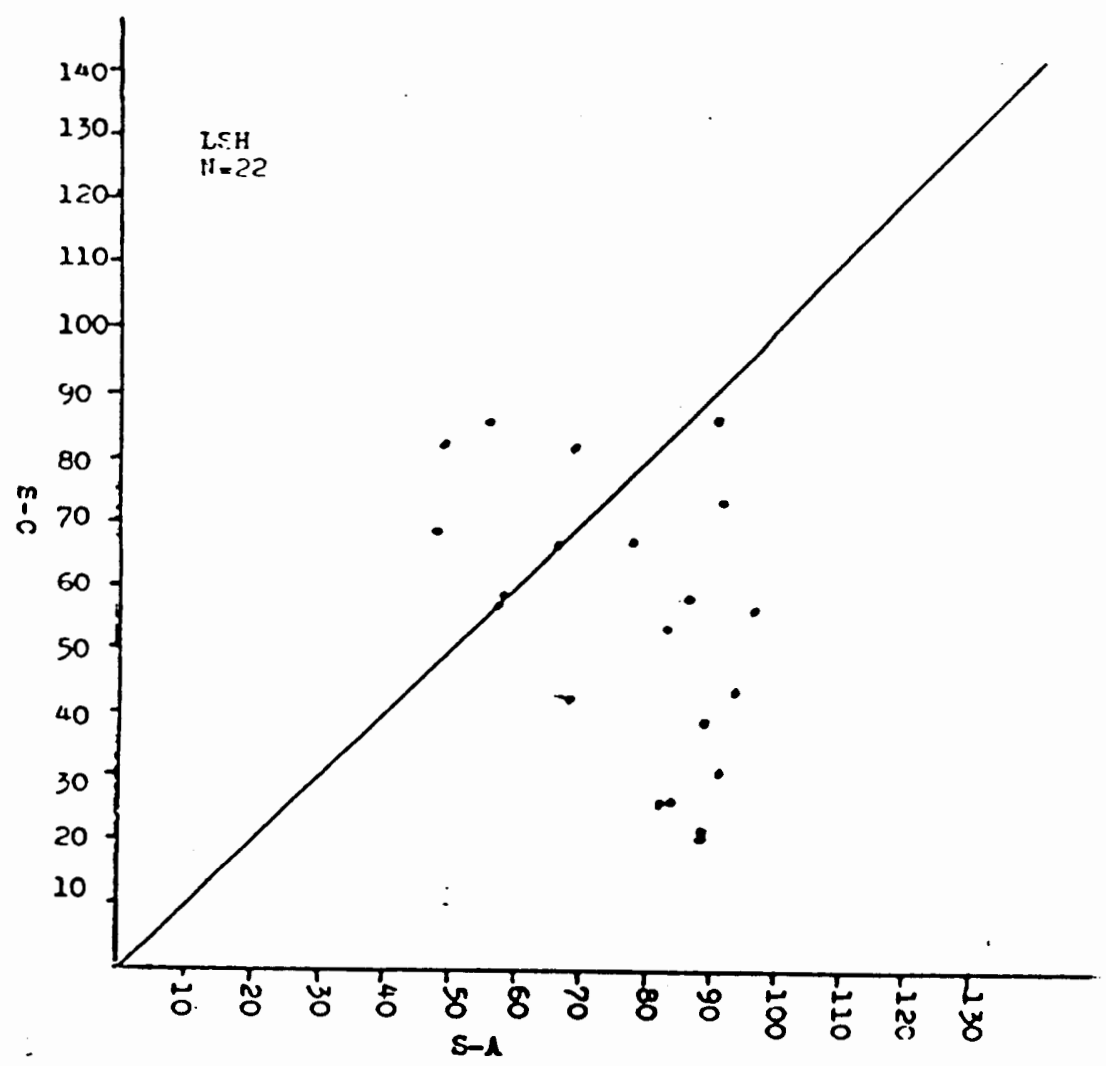

59

Figure 15. Scatter plots for group LSH

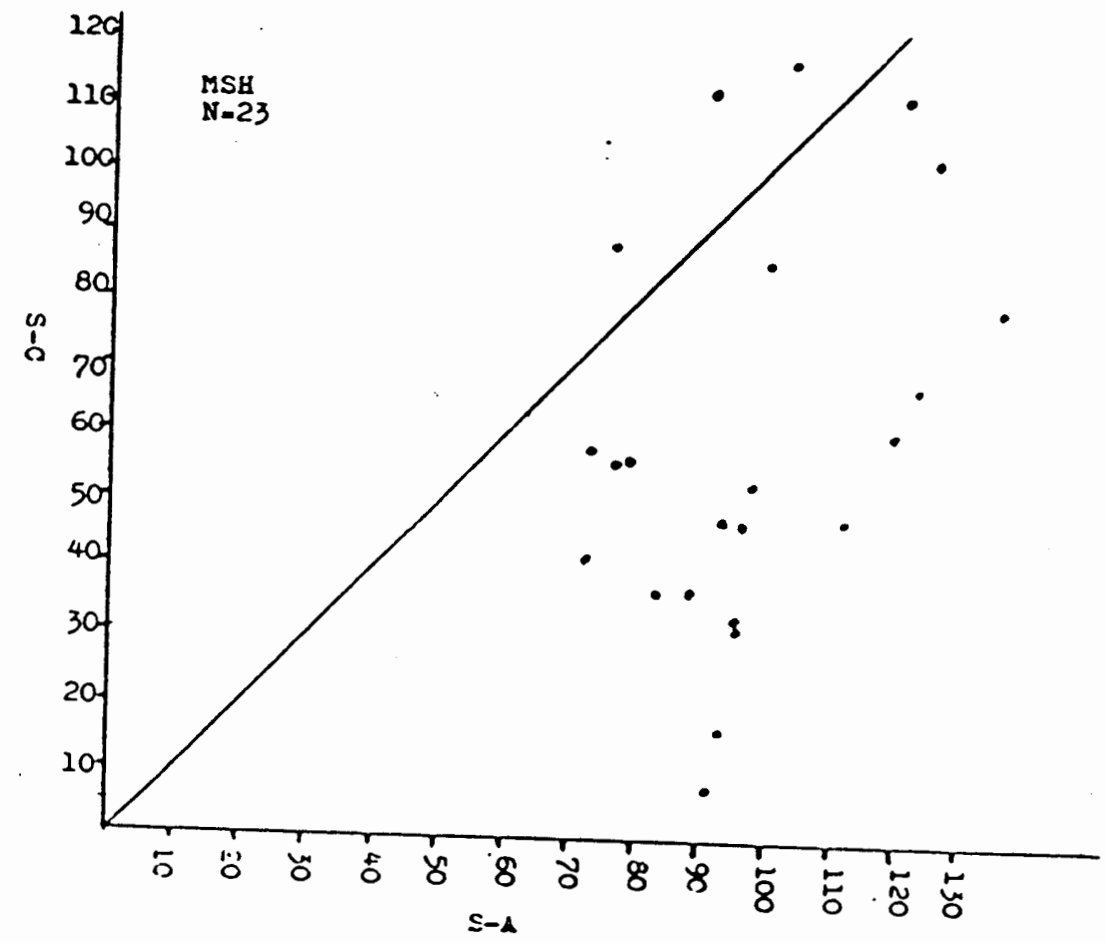

Figure 16. Scatter plots for group MSH 


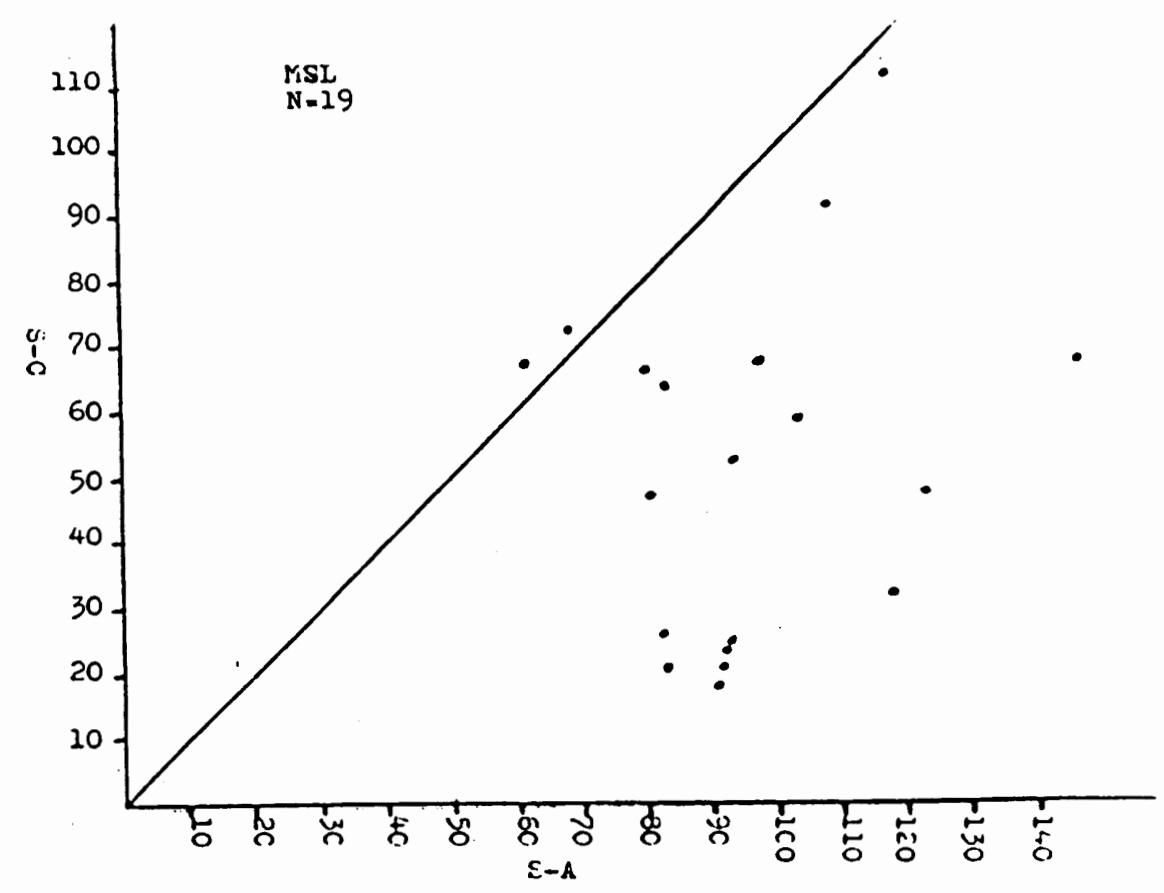

Figure 17. Scatter Plots for Group MSL

As a whole, none of the hypotheses were supported by the data obtained through the Professed Difference in Attitude Questionnaire. A description of the limitations that might cause these contradicting results follows.

\section{Limitations}

In most research, limitations due to sampling, researcher's bias, or research method are quite cormon. Cross-cultural research is no exception to these limitations. Moreover, there will be some unique limitations due to the cultural and language differences between researchers and subjects and the great cultural diversity among subjects.

In cross-cultural research, language is often a barrier and a 
potential limitation. In this research, English was the one of the co-variable, yet only students who were able to understand the vocabulary in the questionnaire could be the subjects of this study. This involvement of only the subjects with higher language proficiency as well as the involvement of college students only may have homogenized the subjects for the present study. Thus, the sample might not be representative. Another source of this limitation lay in the difficulty of obtaining subjects who scored 80 or more on the Michigan Test. In this study only 17 scored this high; this was far less than what the researcher wanted.

The representativeness of the model to the theory and abstract concepts can be another limitation. This study attempted to transfer the abstract concepts into a geometrical configuration. However, this always generates some gap between the verbal theoretical description and the geometrical description due to the different levels of abstraction. The geometric figure cannot represent all the complexity of abstract concepts and theories. This study was not free from this Iimitation.

The third kind of limitation lies in the method of data analysis. This limitation should be stated by the researcher. Although the advancement of computer technology enables us to apply various advanced techniques for data analysis, the analysis should be done by common statistical methods. This allows other researchers to replicate the whole study, using basic statistical knowledge and skills.

The truthfulness of response on the professed difference in the questionnaire is a common limitation for this kind of research. Since students' scores on the Professed Difference in Attitudes Questionnaire 
had to be computed to find the correlation with the Michigan Test scores, students had to provide their names on the questionnaire. However, in order to alleviate this problem, students were given the choice of taking or not taking this questionnaire. Yet the truthfulness of their professed difference was within the researcher's assumption of their being honest. Acknowledging these limitations, the research nevertheless attempted to present a partial replica of the earlier study on second language learning and the acculturation process. The following chapter will include a more extensive discussion of the data results incongruous with the original study. 


\section{CHAPTER SIX}

\section{DISCUSSION AND SUGGESTIONS}

Although the idea that a relationship between language proficiency and cultural sensitivity is intuitively appealing, no direct positive correlation between the two was found in this study. Why did this study come out with different results from Acton's? This discussion will focus on the search for reasons for these results which are incongruous with the original study. Various types of weaknesses are considered as the source of contradicting results from the original study.

First, Acton's equidistance as the optimal distance for successful language learning contradicts his group analysis done by the method of Small Space Analysis (SSA). This analysis interprets the basic data as the set of values attached to each adjective in the questionnaire by all subjects in a group. This set of values, then, is constructed into a representation of the structure of the group's judgment (Acton 1979). In the SSA group level analysis in Acton's study, the equidistance appears to be symptomatic of problems. Acton speculates that the two analyses focus on different things. The SSA focuses on higher level group analysis, and the relative analysis on individual differences. However, if the equidistance is a strong factor to facilitate effective second language learning, it should be supported on both levels. This weakness can be a source of contradicting results between Acton's study and this study. 
Secondly, the small number of subjects for each study should not be ignored. Although Acton had 129 subjects, there is an average of only 30 members for each group. This is not a great number. This study had 65 subjects in three groups. This is far less than what the researcher wanted, for quantitative research with small samples often reflects individual differences rather than the general trend in the group.

A third factor that might be considered as the cause of contradicting results is the juxtaposition of three levels ( $S-C-A)$, which might have made the subject's self reports somewhat suspect. When subjects see three levels juxtaposed in one block, they may tend to report either one of the two extreme, by claiming no differences or by intentionally reporting more differences than necessary. Two pair of adjectives may not have been enough to alleviate this tendency. Moreover two pairs are far too few to get the full view of a learner's concept perception.

In order to avoid these same problems in future studies, they will be discussed in four different areas: (1) biculturality, (2) length of residence and distance between the self and the American culture, (3) marginality, and (4) the Michigan test.

\section{(1) Biculturality}

Acton claimed that the equidistance from the two cultures was the optimal distance for successful language learning. This study attempted to interpret this phenomenon as cultural sensitivity which is manifested in a bicultural person, but it was found that this equidistance as cultural sensitivity did not have any significant association with second language learning. This result contradicts 
Acton's study.

The most plausible explanation for the incongruous results is that cultural sensitivity might not be an appropriate description of Acton's equidistance. Although Adler (1982) and Lum (1982) indicate the influence of two cultures on a bicultural person as his creating some transposition in the total psychocultural posture by forming a unique psychological milieu for himself, there may be some other element that is more pertinent for a bicultural person. The ability to shift one's frame of reference might be more significantly related to cultural sensitivity. A bicultural person can shift his frame of reference from situation to situation whenever it is required, and yet maintains a healthy state of mind (Novak 1970). The PDAQ cannot measure such shifting of one's frame of reference. At least Acton's equidistance in relative analysis was not supported in this study. Bieri's study (1955) which measures a subject's empathic ability might be a more suitable measurement of sensitivity through shifting one's frame of reference. The shifting ability is more likely to be the significant element of cultural sensitivity for being bicultural. Since the association between biculturality and successful second language learning is still appealing, future research endeavors in this area are needed.

(2) Length of Residence and Distance from the American Culture

Although no positive association between the AS scores (the distance between the Americans and the Self) and language proficiency was found, length of residence in this country appeared to have some influence on distance between the self and the American culture. The result of the data analysis indicates that subjects claim the smaller 
distance when they come in to this country but somehow increase it after a certain period of residence in this country.

The increased distance from Americans after more than six months of residence implies that (1) subjects may not get into the state of anomie as soon as Acton (1979), Gardner and Lambert (1972) suggested, and (2) subjects may be experienicing culture shock. Anomie is the state of mind in which a person feels detached from both the native and the target language cultures with mixed feelings of uncertainty and chagrin. This situation should appear as marginality in this study. Acton, Gardner and Lambert use the term, anomie, as one of the characteristic stages of mastery of the second language, where the learner starts thinking and even dreaming in the second language. In Gardner and_Lambert's study ( 1972 ) anomie occurs within a six-week training session, and in Acton's study (1979) within four months. These periods of time are considerably shorter than those found in this study.

The above situation might be due to (a) the difference in the subjects' initial proficiency, (b) the difference in intensity of their immersion in the target culture and (c) the difference in distribution of subjects.

If the subjects had come to this country with extremely high language proficiency, they would likely experience marginality in a relatively short time. However, this is not the situation in this study, because subjects who have been in the U.S. for less than six month showed less distance from the host culture. This is exactly the opposite phenomenon from the earlier studies.

The time difference of anomie may be due to the difference in 
intensity of the subjects' immersion in the target culture. If the subjects stay among Americans all the time, they would likely experience anomie sooner than those who are among Americans only when they take second language courses.

Another difference is in the distribution of subjects. Gardner and Lambert's study (1972') involved only English speaking subjects who study French as a second language. Acton had 388 Japanese and 348 Spanish speaking subjects; on the other hand, this study involved 348 Japanese, 188 Chinese and only 4.58 Spanish speaking subjects.

TABLE XI

PERCENTAGE OF SUBJECTS BASED ON THEIR NATIVE LANGUAGE

$\begin{array}{lccrcrc} & \text { Japanese } & \text { Spanish } & \text { Farsi } & \text { Arab } & \text { Chinese } & \text { Others } \\ \text { Ikeda } & 348 & 4.58 & 4.58 & 98 & 188 & 308 \\ \text { Acton } & 388 & 348 & 11.58 & 8.58 & 08 & 98\end{array}$

The difference in distribution of subjects may be responsible for the contradictory results. Especially the ratio difference in Spanish speaking subjects and Oriental language speaking subjects is crucial for the discussion of anomie. The greater percentage of Spanish speaking subjects in Acton's study might have had some effect on the relatively short period of time before subjects experiencing anomie.

First the linguistic and cultural difference between English and Spanish is relatively small compared to English and Japanese or Chinese. Secondly, certain personal traits inherent in Oriental students could have some effect on anomie, and thus on second language learning. However, this suggestion is only speculation and need to be explored more in detail in future studies.

The second implication is that the subjects are experiencing culture shock. Despite the - unchanging distance between Self and the 
Countrymen (SC), the distance between the Americans and Self (AS) increases. This indicates the transition from euphoria to culture shock or culture stress. Students move into this country with some positive and exciting feelings toward the new language and culture. Later they find some difficulty in their daily routine and experience some psychological distance from the American culture.

According to Gullahorn and Gullahorn (1963) sojourners in foreign countries go through the U-curve adjustment process. The U-curve indicates that the depressing period occurs about the middle point of the sojourning period. It is also very uncommon for sojourners to recover from culture shock in less than six months (Foster 1965, Brein and David 1975). This leads the researcher to consider that the subjects of this study who have spend more than six months are likely to be experiencing culture shock.

As for the group of subjects who have stayed in this country less than six months, the average length of residence (LOR) is 3.0 months and their average of intended length of residence is 37.8 months. These two numbers indicate that the subjects in this group are still at the very beginning stage of their intended stay. They are only one tenth of their way. On the other hand, the group of subjects who had spent more than six months in this country revealed that they had already spent about one third of their intended length of residence. Their average length of residence is 14.4 months and their intended length of residence is 42 months. They are most likely experiencing culture shock. 
TABLE XII

LOR AND INTENDED LOR

$\begin{array}{lcccc} & & \text { SUBJECTS } & \text { LOR } & \text { INTENDED LOR } \\ \text { GROUP (1) } & 21 & 3.0 & 37.8 \\ \text { GROUP (2) } & 33 & 14.4 & 42.0\end{array}$

The interpretation of the period of culture shock is different from that of Acton's study (1979). However, it is clear that both LOR and intended LOR, and their relation have some influence on perception of connotation and attitudes. This is a significant point that should be clarified in future studies.

\section{(3) Marginality}

There are two problems that should be elucidated; the first problem is the unclear definition of marginality, and the second, diversity in learning style.

Since marginality is too simplistically defined in the geometric triangular model, the model cannot represent the full scope of marginality which actually includes various types and aspects. In the model, marginality is represented by the height (or altitude) of point $\mathrm{S}$ from the bottom line of $\mathrm{CA}$.

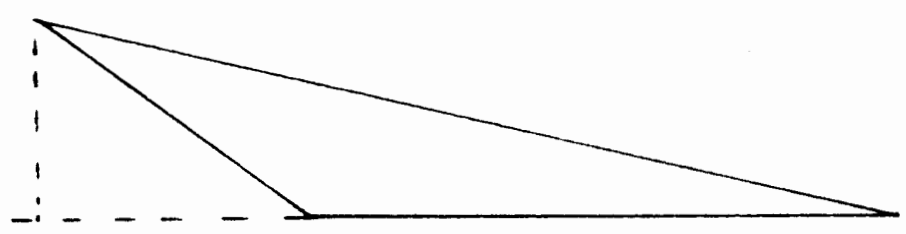

Figure 18. An example of triangular model

This reveals two salient problems. First, the altitude, which is interpreted as marginality, includes several types of marginality which 
have not been differentiated clearly. Three types of marginality should be considered. The first type of marginal person is marginal from both cultures and cannot participate in either of them. The second type of marginal person is also marginal from both cultures, but can operate in both cultures effectively by shifting his frame of reference. The third type of marginal person is marginal from only one of the cultures. The second and the third types are most problematic in terms of representativeness in the geometric model. The second type appears to be as equally marginal as the first type, yet the nature of marginality is totally different in terms of the ability to shift frame of reference intentionally. The third case does not appear as high marginality score (h) as shown below.

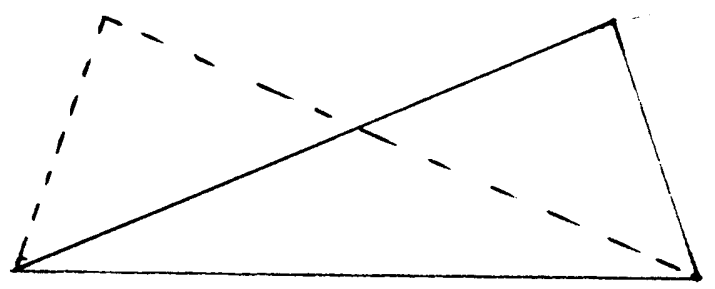

Fiqure 19. A triangle with low marginality

Thus, the great marginality from one culture does not appear as a high "h" score, i.e., high marginality. However, the biculturality score derives its ethnocentrism by being far from the midpoint as shown in figure 19. Thus, the interpretation of the data in terms of marginality was too simplistic. The model for marginality should be further developed so that it can account for various types of marginality as illustrated in figure 19.

Another problem is that there are various learning styles which were not given consideration in this study. This can be a source of 
distortion of the data on marginality. Although Kolb (1979) emphasizes the necessity of all four skills, abstract conceptualization, reflective observation, concrete experience, and active experiential skills, in effective experiential learning some people may simply use one type of skill more than another. It is possible that a learner uses little reflective observation skill and abstract conceptualization skill, but he absorbs more knowledge by applying more emphatically concrete experience and active experiential skills, the skills that require little marginality from the process. These are some speculations which can be explored in future studies. Since many studies in the field of teaching English as a second language (TESL) emphasize the benefit of teaching some rules in adult language learning, there must be some way to test the importance of marginality or cultural awareness in second culture and language learning. More studies are needed in this area.

\section{(4) Michigan Test}

Although the Michigan test has a high correlation with the Michigan test battery and other major language proficiency tests such as TOEFL (Test of English as a Foreign Language), it basically is a grammar test. It consists of a grammar test, a vocabulary test, and a reading comprehension test. There is no major proficiency test that includes speaking ability, which is a very salient skill in communication. Therefore, the validity of the Michigan test and the Michigan battery as a measurement tool should be questioned.

Conclusion

Acton's research findings of socio-cultural equidistance from the 
native and the target language cultures as the optimal distance for successful language learning were not supported in this study. In this study, the equidistance is interpreted as sensitivity which is pertinent to biculturality; however, no positive association was found between biculturality and language proficiency. The results inconsistent with Acton's study might be due, first, to the weakness of his own theory. Equidistance may not be an optimal distance for successful language learning. Further study is required to support or reject this theory. Second, the small sample size is a possible cause for unexpected results from the hypotheses. Third, the format of the questionnaire can be considered as a source of contradicting results. There is some leeway for improvement.

Some difficulties and problems in four areas were discussed. The description of biculturality was questioned. The ability of shifting frame of reference was brought up for future consideration as a more salient factor for being bicultural. The distance between self and Americans (the target language culture) might be better treated as the function of culture shock rather than anomie. Yet the discrepancy between the original study and this study in this S-A ( Self and Americans) score can be attributed to the difference in subject distribution. The relationship between the IOR (Length of Residence) and intended IOR may have some effect on attitudes. These questions should be addressed in future studies.

In regard to marginality, two problems were brought into discussion. One is a need for a more refined definition of marginality. The other is a suspicion about the irrelevance of marginality in certain learning styles. 
This partial replication, with some modification, of William Acton's (1979) study did not support his findings; socio-cultural equidistance did not appear to be an indication of successful second language learning. Questions and problems raised by this study should be reconsidered in future studies.

\section{Suggestions}

Although various suggestions for future studies were mentioned throughout this chapter, following are some other suggestions.

(1) The PDAQ should be tested once more to find out its reliability on the association between socio-cultural equidistance and second language proficiency.

(2) The PDAQ should be used for longitudinal studies to see if it can reflect changes in perception due to acculturation.

(3) It might be interesting to compare the PDAQ results with studies, like Bieri's (1955), that measure shifting of frame of reference.

(4) The PDAQ result should also be compared with speaking ability in order to improve the validity as a measurement tool.

(5) The relationship between the IOR and the intended IOR should be more carefully observed.

The relationship between biculturality and successful language learning is still intuitively appealing. It is very important to pursue the study to find out how the second language learning process relates to the acculturation process. A clear view will certainly help second language teachers as well as learners who try to communicate in their second language while they are in the process of acculturation. 
REFERENCES

Acton, W. R. (1979). Perception of Lexical Connotation; Professed Attitude and Socio-cultural Distance in Second Language Learning. Ann Arbor, Mi: University Microfilms International

Adler, P. (1982). Beyond cultural identity: Reflections on cultural and multicultural man. In Samovar, L. and Porter, R. (Eds.) Intercultural Communication: A Reader. Belmont, Cal.: Wadsworth Publishing Co. (pp 389-406)

Barna, L. M. (1976). How culture shock affects communication. A paper presented in the Distinguished Scholars Program at the 1976 Communication Association of the Pacific Annual Convention

Barnlund, D. (1982). Communication in a global village. In Samovar, L. and Porter, R.: Intercultural Communication: A Reader. Belmont, Cal.: Wadsworth Publishing Co. (pp 4-15)

Bem, D. J. (1970) . Belief, Attitudes, and Human Affairs. Belmont, Cal: Brooks/Cole Publishing Co.

Bennett, M. J. (1977) . Forming/feeling process: communication of boundaries and perception of patterns. A thesis submitted to the faculty of the graduate school of the University of Minnesota

Bennett, M. J. (1984) . Towards ethnorelativism: A developmental model of intercultural sensitivity: A paper presented at Annual Conference of the Council on Intermational Educational Exchange at Minneapolis, Min., Nov. 1984

Benson, P. G. (1978). Measuring cross-cultural adjustment: The problem of criteria. In International Journal of Intercultural Relations. Vol. 2-1: (pp 21-37)

Berger, P. and Luckman, T. (1967) . The Social Construction of Reality. New York: Ancor Books

Berry, J. W. (1975) . Ecology, cultural adaptation, and psychological differentiation: traditional patterning and acculturaive stress. In Brislin, R. W., Bochner, S. \& Lonner, W. J. (Eds.) CrossCultural Perspectives on Learning. New York: John Wiley \& Sons

Berry, J. W. (1979). Psychological aspects of cultural pluralism: unity and identity reconsidered. In Brislin, R. W. (Ed.) Culture Learning. Hawaii: The University Press of Hawaii (pp 18-23)

Bieri, J. (1955) . Cognitive complexity-simplicity and predictive behavior. In Journal of Abnomal Psychology and Social Psychology Vol. 51: (pp 263-268)

Bochner, S. (1979). The mediating man and cultural diversity. In Brislin, R. W. (Ed.) Culture Learning. Hawaii: The University Press of Hawaii. (pp 3-17) 
Brein, M. \& David, K. H. (1975). Inter cultural communication and adjustment of the sofourner. In Perdersen, P. (Ed.) Readings in Intercultural Communication. Vol.4: (pp 32-54)

Brislin, R. W., Bochner, S. and Lonner W. (Eds.) (1975) - Crosscultural Perspectives on Learning. New York: Wiley.

Brislin, R. W. (1979) . Culture Learning: Concepts, Applications, and Research. Hawaii: The University Press of Hawaii

Brislin, R. W. (1981) - Cross-Cultural Encounters. New York: Pergamon Press

Brown, D. H. (1980a) - Principles of Language Learning and Teaching (pp101-145). Englewood Cliffs, N.J: Prentice-Hall

Brown, D. H. (1980b). The optimal distance model of second language acquisition. In TESOL guarterly, Vol.14 (pp 157-164)

Burling, R. (1970). Man's Many Voices: Lanquage in Its Cultural Context New York: Holt, Rinehart and Winston

'clarke, M. A. (1976). Second language acquisition as a clash of consciousness. In Lanquage Learning. Vol.26-2: (pp 377-389)

Condon, J. C. Jr. (1975) . Semantics and communication (2nd ed.). New York: Macmillan Publishing

Fathman, A. K. (1976) . Variables affecting the successful learning of English asasecond language. In TESOL Quarterly. Vol.10:(pp 433-441)

Fillmore, L. W. (1979). Individual difference in second language acquisition. In Fillmore, C. J. (Ed.), In Individual Differences in Ability and Lanquage Behavior. (pp 203-228) N.Y: Academic Press

Foster, G. M. (1965). Traditional cultures: And the Impact of Technological Change. New York: Harper \& Row

Freedman, A. (1980). A strategy for managing "cultural" transitions: Reentry from training. In Pfeiffer, W. J. \& Jones, J. E. The 1980 Annual Handbook for Group Facilitators. San Diego, Cal.: University Associates

Gardner, R. C. (1977). Social psychological aspects of second language acquisition. In Giles, $\mathrm{H} \&$ St. Clair, R. (Eds.), Language and Social Psychology. (pp 193-220) Oxford, England: Basil Blackwell Mott.

Gardner, R. C. and Lambert, W. E. (1972). Attitudes and Motivation in Second Language Learning. Rowley, Mass.: Newbury House Publishers 
Gardner, R. C. and Taylor, D. M. (1968). Ethnic stereotypes: Their effects on person perception. In Canadian Journal of Psychology. Vol.22-4: (pp 267-276)

Gingras, R. C. (1978). Second-Lanquaqe Acquisition \& Foreign Lanquage Teaching. Washington D. C.: Center for Applied Linguistics

Goodrich, G. C. (1977). Distractor efficiency in foreign language testing In TESOL Quarterly. Vol.11-1: (pp69-78)

Guilford, J. P. (1956). Fundamental Statistics in Psychology and Education. New York: McGraw-Hill (p 145)

Guiora, A. Z., Beit-Hallahmi, B., Brannon, R.C.L., Dull, C.Y., \& Scovel T. (1972a). The effects of experimentaly induced changes in ego states on pronunciation ability in a second language: An exploratory study. In Comprehensive Psychology. Vol.13-5: (pp421-428)

Guiora, A. Z., Brannon, R.C.L., \& Dull, C. Y. (1972b) . Empathy and second language learning. In Lanquage Learning. Vol.22-1, (pp 111-130)

Guiora, A. Z., Paluszny, M., Beit-Hallahmi, B., Catford, J., Cooley, R. \& Dull, C.Y. (1975). Language and person: Studies in language behavior. In Lanquage Learning. Vol.25-1, (pp 43-62)

Gullahorn, J. T., \& Gullahorn, J. E. (1963). An extension of the Ucurve hypothesis. In Journal of Social Issues. Vol.19-3, (pp 33-47)

Hale, T. M., \& Burdar, E.C. (1970). Are TESOL class the only answer? In Modern Lanquage Journal. Vol. 54, (pp 487-492)

Hall, E. (1973). The Silent Language. New York: Anchor Press

Hall, E. (1977) - Beyond Culture. New york: Anchor Press

Hallowell, Irving A. (1957). Sociopsychological aspects of acculturation In Linton, R. (Ed.), The Science of Man in the World Crisis. Columbia University Press

Hamayan, E. Genesee, F. \& Tucker, G. R. (1977). Affective factors and language exposure in second language learning. In Lanquage Learning. Vol. 27-2: (pp 225-241)

Henle, P. (1972) . (Ed.) Language Thought \& Culture, Ann Arbor: The University of Michigan Press

Hoijer, H. (1982). The Sapir-Whorf Hypothesis. In Samovar, L.A. and Porter, R.E. (Eds.). Intercultural Communication: A Reader (3rd. Ed.). Belmont, Cal.: Wadsworth Publishing Co. (pp 210-217)

Hoopes, David S., \& Pusch, M. D. (1979) Definition of themes. In Pusch, M. (Ed.), Multicultural Education: A Cross Cultural Training Approach. La Grange Park, Ill.: Intercultural Network 
Inhelder, B. and J. Piaget. (1958) The Growth of Logical Thinking From Childhood to Adolescence. New York: Basic Books

Janes, S. E., Haiman, F. S., and Barnlund, D.C. (1980). The Dynamics of Discussion. New York: Häper \& Row

Kelly, G. A. (1955) The Psychology of Personal Constructs. New York: Norton.

Kim, Y. Y. (1978). Communication patterns of foreign immigrants in the process of acculturation. In Human Communication Research Vol. 4-1: (pp 66-77)

Kim, Y. Y. (1979) . Toward an interactive theory of communication/ acculturation. In Nimmo, D. (Ed.) Communication Yearbook. New Jersey Transaction Books (pp 435-453)

Kolb, D. and Fry, R.. (1979) . Experiential learning theory and learning experiences in liberalarts education. In New Directions for Experiential Learning: Enriching the Liberal Arts Through Experiential Learning. San Francisco, Ca.: Jossey-Bass

Kolers, P. A. (1963). Interlingual word associations. In Journal of Verbal Learning and Verbal Behavior. Vol.2: (pp 291-300)

Krashen, S. D. (1973). Lateralization, language learning, and the critical period: Some new evidence. in Language Learning. Vol. 23 (pp 63-71)

Krashen, S. D. (1976). Formal and informal linguistic environments in language acquisition and language learning. In TESOL Quarterly. Vol. 10-2: (pp 157-168)

Krashen, S. D., Long, M.A., \& Scarcella, R.C. (1979). Age, rate and eventual attainment in second language acquisition. In TESOL guarterly. Vol.13: (pp 573-582)

Krashen, S. D. (1980) The monitor model for adult second language performance. In Croft, K. (Ed.): Reading on English as a Second Language (2nd ed.) . Cambridge, Mas.: Winthrop Publishers, Inc. (pp 213-221)

Lambert, W. E. (1967) . A social psychology of bilingualism. In Journal of Social Issues. Vol.23-2 : (pp 91-109)

Larson, D. N. and Smalley, W. A. (1972) Becoming Bilingual: A Guide to Lanquage Learning. New Canaan, Conn.: Practical Anthropology

Lukmani, Y. M. (1972) Motivation to learn and language proficiency. In Lanquage Learning. Vol. 22-2: (pp 261-273)

Lum, J. (1982) Marginality and Multiculturalism: Another look at bilingual/bicultural education. In Samovar, L. \& Porter, R. (Eds.) Intercultural Communication: A Reader. Belmont, Ca.: Wadsworth Pub. (pp 384-388) 
McLaughlin, B. (1978). The monitor model: Some methodological considerations. In Language Learning. Vol.28-2: (pp 309-332)

Mead, G. H. (1934) . Mind, Self and Society. Chicago, Ill.: University of Chicago Press

Novak, M. (1970). The Experience of Nothingness. New York: Harper and Row, Publishers

Ogden,C.K. and Richards, F.G. (1949). The Meaning of Meaning. Iondon: Routledge \& Kegan Paul Ltd.

Oller, J. W. Jr., Baca, L. L., \& Vigil, A. (1977a). Attitudes and attained proficiency in ESL; a socio-linguistic study of Mexican Americans in the Southwest. In TESOL Quarterly. Vol.11-2 (pp 173-184)

Oller, J. W. Jr., Hudson, A., \& Liu, P. F. (1977b). Attitudes and attained proficiency in ESL; a sociolinguistic study of native speakers of Chinese in the United States. In Lanquage Learning. Vol. 27-1 (pp 1-28)

Osgood, C. E., Suci, G., and Tannenbaum, P. (1957). The Measurement of Meaning. Urbana, Ill.: University of Illinois Press

Osgood, C. E., May, W. H., \& Miron, M. S. (1975) - Cross-Cultural Universals of Affective Meaning. Urbana, Ill: University of Illinois Press

Park, R. E. (1928). Human migration and the marginal man. in The American Journal of Sociology. Vol. 33-6: (pp 881-893)

Rosansky, E. J. (1975). The critical period for the acquisition of language; Some cognitive development considerations. in Papers on Bilinqualism. Vol.6: (pp92-102)

Samovar, L. A. and Porter, R. E. (1982). Intercultural Communication: A Reader. (3rd. Ed.) Belmont, Cal.: Wadsworth Publishing Co.

Schumann, J. H. (1975). Affective factors and the problem of age in second language acquisition. In Lanquage Learning. Vol.25-2 (pp 209-235)

Schumann, J. H. (1976). Social distance as a factor in second language acquisition. In Language Learning. Vol.26-1: (pp135-143)

Schumann, J. H. (1977). The pidginization hypothesis. In Hatch, E. M. (Ed.). Second Lanquage Acquisition. Rowley, Mas. Newbury House

Schumann, J. H. (1978). The acculturation model for second language acquisition. In Gingras, R. C. (Ed.) Second Language Acquisition and Foreign Language Teaching. Washington D. C. Center for Applied Linguistics 
Shapira, R. G. (1978). The non-learning of English: Case study of an adult. In Hatch, E. M. (Ed.) Second Lanquage Acquisition, Rowley, Mas. : Newbury House

Shibutani, T. (1955). Reference groups as perspectives. In The American Journal of Sociology. Vol.60 : (pp 562-569)

Singer, M. (1982). Culture: A perceptual approach. In Samover,L. and Porter, R. Intercultural Communication: A Reader. Belmont, Ca.: Wadsworth publishing Co. (pp 54-62)

Spolsky, B. (1969). Attitudinal aspects of second language learning. In Lanquage Learning, Vol.19-3 \& 4 (pp 271-283)

Spolsky, B. (1980) What does it mean to know a language? In Croft, K. (Ed.) Readings on English as a Second Language. Campridge, Mas.: Winthrop Publishers, Inc. (pp 26-42)

Stauble, A. E. (1978). The process of decreolization: A model for second langraage development. In Lanquage Learning, Vol.28-1: (pp 29-54)

Stern, H. H. (1980). What can we learn from the good language learner? In Croft, K. (Ed.) Readings on English as a Second Lanquage (2nd ed.). Cambridge, Mas.: Winthrop Publishers Inc. (pp 54-71)

Stonequist, E. V. (1935). The problem of the marginal man. in The American Journal of Sociology. Vol. 41-1: (pp 1-12)

Tucker, R. K., Weaver, R. \& Berryman-Fink, C. (1981). Research In Speech Communication. Englewood Cliffs, New Jersey: PrenticeHall

Trifonovitch, G. (1977). Culture learning/culture teaching. In Educational Perspectives. Vol.16-4: (pp 18-22)

Useem, J., Useem, R., \& Donoghue, J. D. (1963). Men in the middle of the third culture: The roles of American and non-western people in cros-cultural administration. In Human Organization. Vol. 2122: (pp 169-179)

Walbert, H. J., Hase, K. \& Rasher, S. P. (1978) English acquisition as diminishing function of experience rather than age. In TESOL Quarterly. Vol.12-4: (pp 427-437)

Watson, Karen A. (1979). Understanding human interaction: The study of everyday life and ordinary talk. In Brislin, R. W. (Ed.). Culture Learning. Hawaii: The University Press of Hawaii. (pp 101-110)

Watzlawick, P., Beavin, J. H., \& Jackson, D. D. (1967). Pragmatics of Human Communication. New York: Norton and Company

Watzlawick, P. (1977). How Real Is Real? New York, N.Y.: Randam House 
APPENDIX A

Covering Letter

This is part of a study about how adults learn a foreign language and how they learn about the people and the country where that language is spoken. From this research we hope to get a better idea of how a person's understanding of the new culture influences his ability to learn the language.

Thank you for your cooperation.

Kazuko Ikeda

Demographic Questionnaire

Name :

Native Language:

Native Country

How many months have you been in the U.S.?

In what year did you graduate from high school?

If you have attended a university, what degree do you have?

In what field?

How long do you plan to stay in the U.S.? 
Professed Difference in Attitude Questionnaire ThLiVISION

C NOT VALUABLE

C hONEST
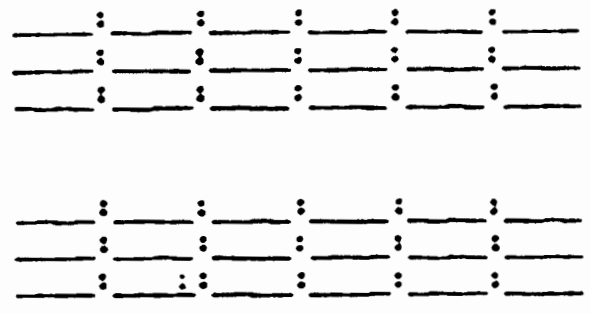

THE UNITED STATES
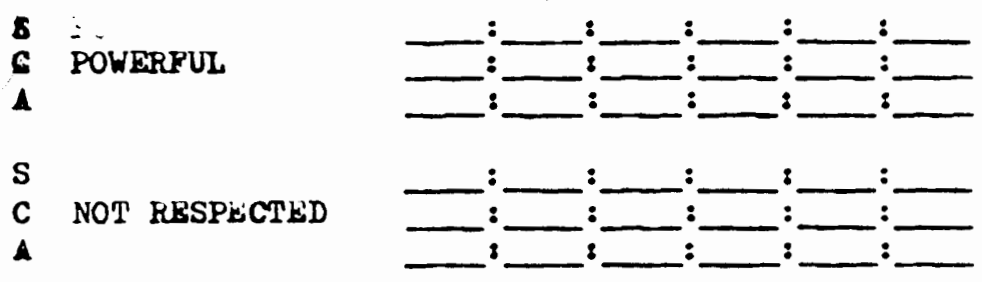

POWIRLESS

FATHER
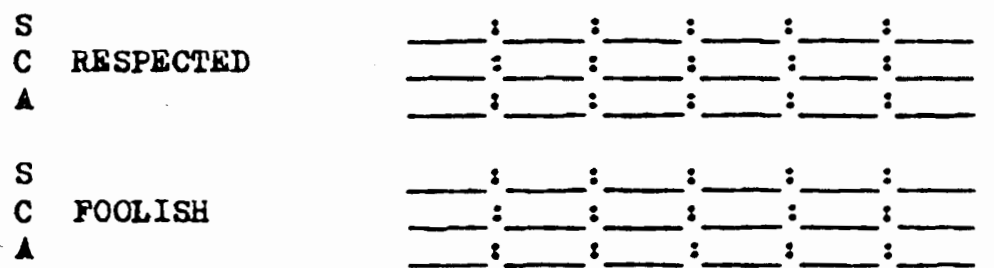

NOT RASPECTED

RESPECTLD

DI SHONEST

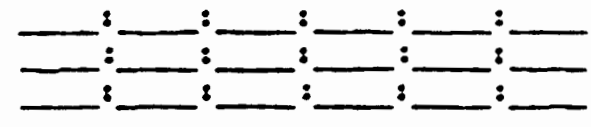

WISE

\section{CENSORSHIP}
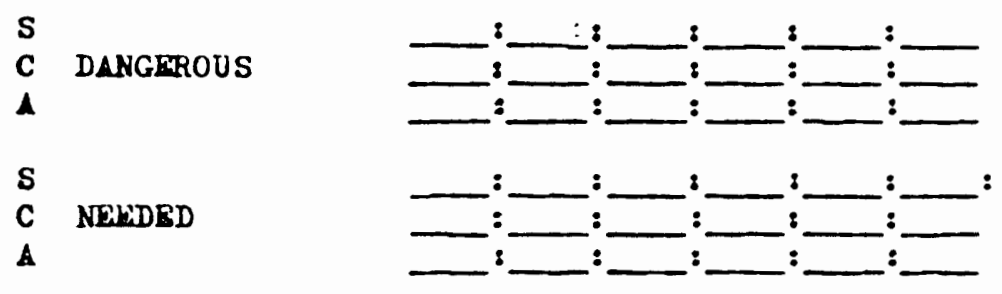

SAPE

AMERR ICAN WOMEN
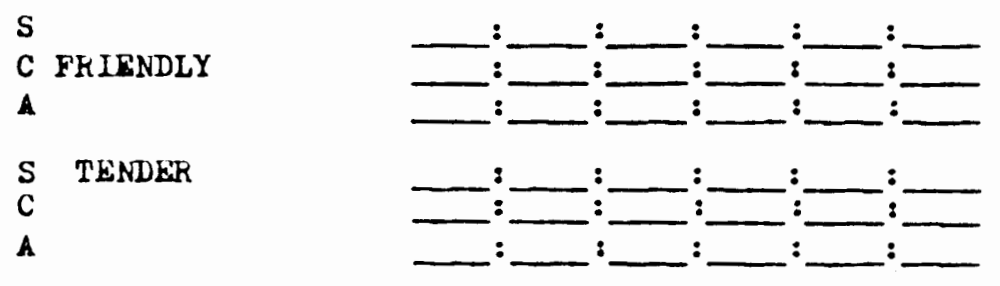

UNFR IENDLY

TOUGH 
ThE OLYMPIC GANES
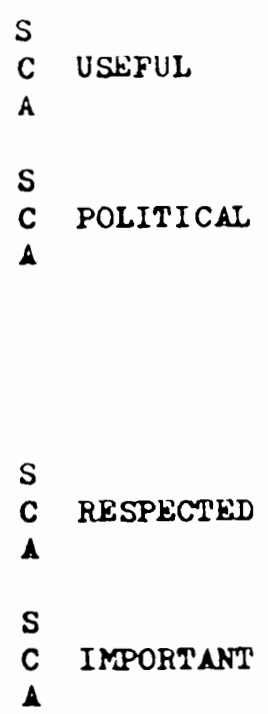
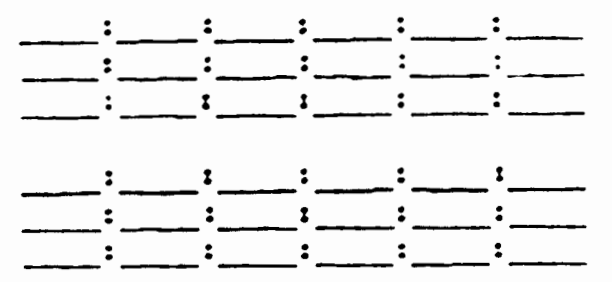

$$
\begin{array}{ll}
\text { C } & \\
\text { A } & \\
\text { S } & \\
\text { C IMPECTED } \\
\text { A IMPONANT }
\end{array}
$$

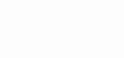

\section{NEW SPAPERS}

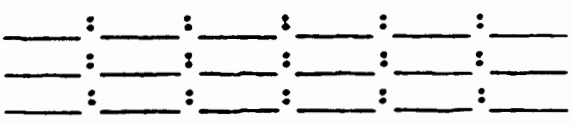

NOT RESPECTED

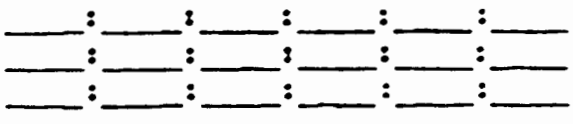

BIRTH CONTROL

$$
\begin{array}{ll}
\text { S } & \\
\text { A } & \text { NERDED } \\
\text { S } & \\
\text { C } & \text { BND } \\
\text { A } &
\end{array}
$$

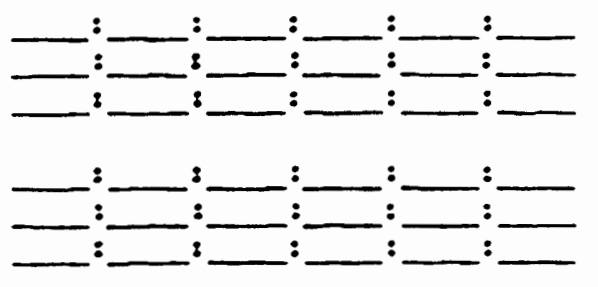

NOT NEEDED

THE UNITED NATIONS

$$
\begin{array}{ll}
\text { S } & \\
\text { C } & \text { UNIMPORTANT } \\
\text { A } & \\
\text { S } & \\
\text { C } & \text { WEAK } \\
\text { A } &
\end{array}
$$

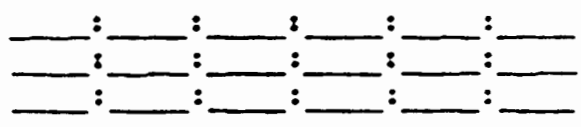

IMPORTANT

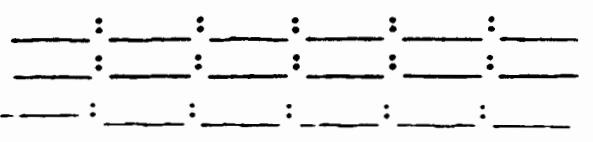

PSYCHOLOGY

$$
\begin{array}{ll}
\text { S } & \\
\text { C } & \text { UShTESS } \\
\text { A } & \\
\text { S } & \\
\text { C } & \text { Dubip } \\
\text { A } &
\end{array}
$$

USERUL,

SHALLOW 


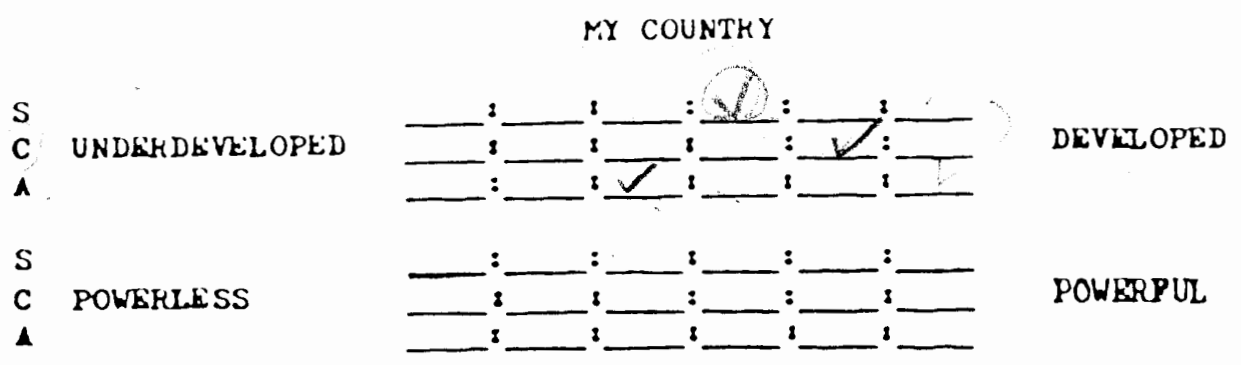

OLD PEOPTS
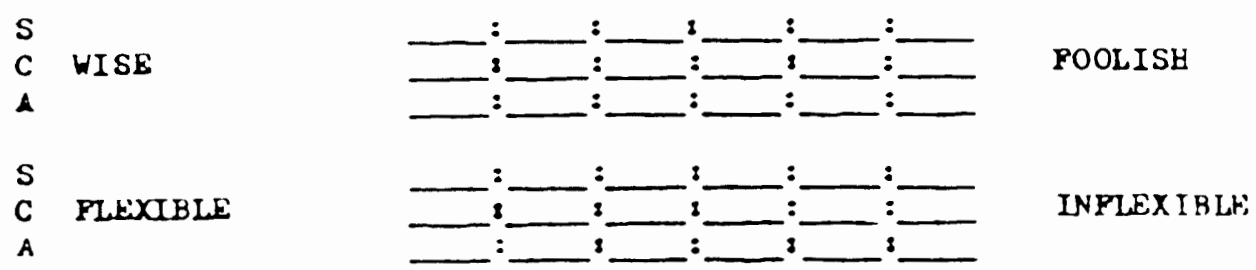

RRLIGION
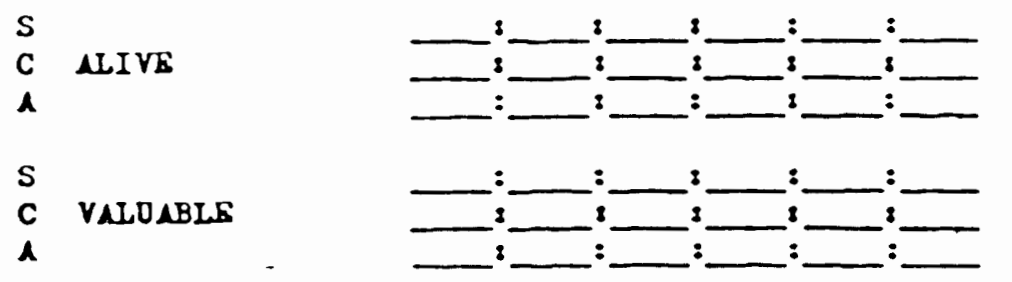

DEAD

THE FUTURE

$\begin{array}{ll}\text { S } & \\ \text { A DANGEROUS }\end{array}$

C HAPPY

A

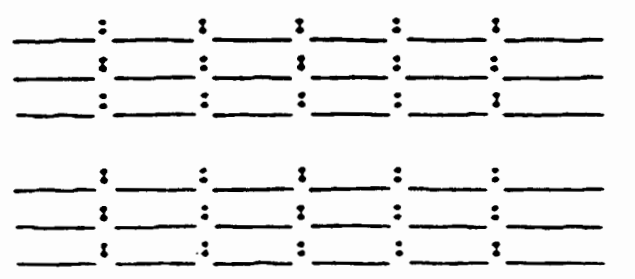

SAPE

POOR PEOPLE
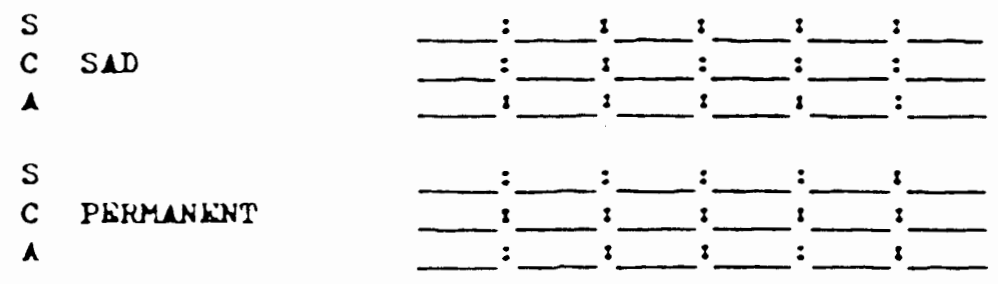

HAPPY

TEMPORARY 


\section{CHILDREN}

C NOT NESDND

$\Lambda$

S

C POWERPUL

$\boldsymbol{A}$
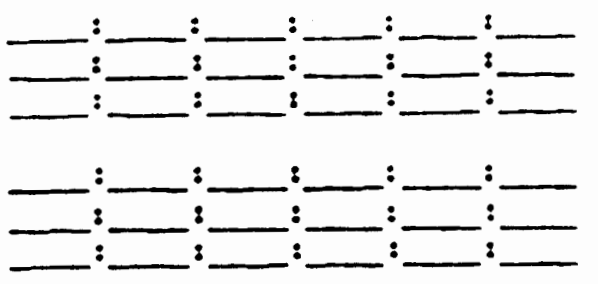

DI VORCE

C NECESSARY

$\Lambda$

s

C $\operatorname{COOD}$

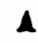
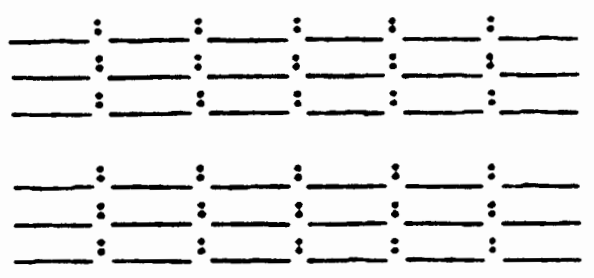

$B \perp D$

LABOR UNIONS

$$
\begin{array}{ll}
\text { S } & \\
\text { C } & \text { HONEST } \\
\text { A } & \\
\text { S } & \\
\text { C } & \text { NEEDED } \\
\text { A } &
\end{array}
$$
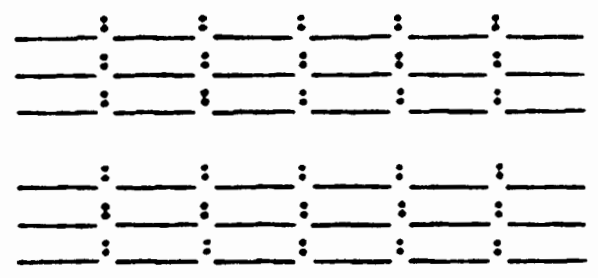

\section{AMGRICANS}

$\mathbf{S}$

C UNFRIENDLY

$\boldsymbol{A}$

$\mathrm{S}$

C EMOTIONAL

$\boldsymbol{A}$

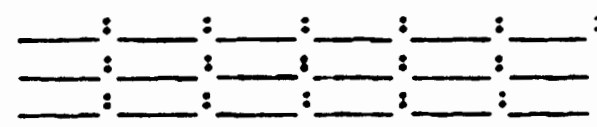

FRIENDLY

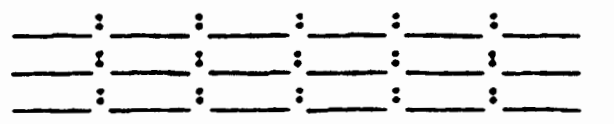

LOGI CAL

\section{NAKEDNESS}

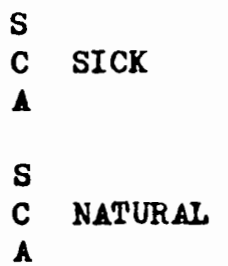

NEEDED

POWERLESS
DI SHO NEST

NOT NEEDED
HEALTEI

UNNATURAL 